\title{
Three-dimensional characteristic of fungiform papillae and its taste buds in European bison (Bison bonasus), cattle (Bos taurus), and Bison bonasus hybrid
}

\author{
Barbara Plewa, Kinga Skieresz-Szewczyk and Hanna Jackowiak
}

\begin{abstract}
Background: Our recent macro- and scanning electron microscopic study of tongue conducted on domesticated cattle, wild living European bison, and Bison bonasus hybrid revealed various spatial arrangement and number of gustatory and mechanical papillae between parental species and their hybrid. Furthermore, scanning electron microscopy analysis of gustatory papillae indicated the variable distribution of fungiform papillae (Fu) over the surface of the tongue, which could be significant in differentiated taste perception during feeding in studied wild living and domesticated husbandry ruminants. To specify the detailed microstructure of Fu papillae with connective tissue cores (CTC) and intraepithelial taste buds system, the first time the three-dimensional computer-aided analysis of serial histoslides resulted in the rendering of 3D reconstructions of Fu papillae.
\end{abstract}

Results: The comparative analysis of 3D models Fu papillae conducted in six areas of lingual mucosa of each tongue revealed information about, microstructural diversity of Fu papillae in studied ruminants. The estimation of number and density of Fu papillae on tongues, rate of protrusion of papillae over mucosa, and a number of taste buds per papilla allowed to state the ventral surface of the lingual apex and posterolateral surfaces of the lingual torus as regions important in taste perception, as in the preselection of taken food, as well in the analysis of food during rumination, respectively. On the 3D models were observed three structural types of CTC of different distribution on the tongue in studied species. The quantitative data of the number of taste buds on Fu papillae have regional functional differences in the taste system important in feeding and veterinary practice. Moreover, our analysis determined specific features in examined hybrid and showed similarities of some studied features with cattle, i.e., maternal species.

Conclusions: The 3D reconstruction method used for the first time in the field of study of the lingual papillae and taste buds system can be considered as an innovative and effective tool in assessing of the microstructures of Fu papillae, and it could be suitable for further studies of taste system structures in normal and pathological condition.

Keywords: Fungiform papillae, Taste buds, Ruminants, Bison bonasus hybrid, Cattle, European bison, 3Dreconstruction

*Correspondence: hanna.jackowiak@up.poznan.pl

Department of Histology and Embryology, Poznan University of Life

Sciences, Wojska Polskiego 71C, PL 60-625 Poznań, Poland

\section{Background}

Among lingual papillae observed on mammalian tongues, fungiform papillae (Fu papillae), vallate papillae (Vp papillae), and foliate papillae (Fo papillae) belong to gustatory papillae [1]. The occurrence of each type of gustatory papillae is characteristic in taxonomic orders 
of mammals. Predominantly in primates, carnivore, marsupials, marine mammals, suine, and rodents occur all three types of gustatory papillae [2-9]. However, in bats, insectivores, and some carnivores (cats) or ruminants (cattle, fallow deer, Buffalo, goat, cattle-yak, yak), only Fu papillae and Vp papillae were observed [10-24]. An interesting exception is a hippopotamus, though it belongs to herbivores, only the presence of Fu papillae and Fo papillae were described [25].

Previous macro- and microscopic studies of lingual papillae revealed that in mammalian species $\mathrm{Fu}$ papillae are distributed on the dorsal and ventral surface of the apex and along the body of the tongue [26]. Moreover, in ruminants these gustatory papillae are also observed on the dorsal and lateral surfaces of the lingual prominence $[23,27-30]$. The distribution of Fu papillae vary on the dorsal surface of the lingual apex and body of the tongue, because $\mathrm{Fu}$ papillae may be located along lateral margins of the tongue or spread evenly among filiform papillae $[8,13,27,31,32]$. However, on the ventral surface of the tongue these papillae cover evenly lateral borders of the apex or form characteristic clusters on the border of the lingual apex or on the tip of the tongue $[8,13,23,31,33$, 34].

The studies on the microstructure of $\mathrm{Fu}$ papillae in mammals mostly based on observations in a scanning electron microscope (SEM) and histological sections in light microscopy (LM). In them $\mathrm{Fu}$ papillae were described as dome-shaped structures with the convex or flat dorsal surface, which raise above the mucosa or are deeply embedded in an interpapillary stratified squamous epithelium, so on SEM electronograms, these structures are encircled by epithelial furrow $[3,8,9,12,21,30,31$, 33]. In addition, $\mathrm{Fu}$ papillae are composed of connective tissue core (CTC) covered by keratinized stratified squamous epithelium, which contains taste buds on the dorsal surface of papilla $[26,35]$.

The main function of $\mathrm{Fu}$ papillae is taste perception by receptor cells of taste buds, which function is not only connected with the process of the choice of the food in terms of nutrients, but also with animal protection against toxins [35-40]. So far, data about the distribution and number of taste buds on the dorsal surface of Fu papillae are insufficient $[4,8,22,28,31,33,41,42]$. Till now, it seems to be that the number of taste buds was underestimated. Neither observation of single crosssection of histoslides, nor the assessing the number of taste pores on the surface of Fu papillae, often covered by desquamated keratinized cells, was reliable. Thus, we decided to apply more specific and advanced method, like the three-dimensional analysis, to conducted studies.

Our previous microscopic studies of the tongue and mechanical and gustatory papillae showed the differences between closely related species of ruminants [27]. The differences in the distribution of $\mathrm{Fu}$ papillae in parental species and Bison bonasus hybrid were observed on both the dorsal and ventral surface of the tongue. Evenly dispersed Fu papillae on the whole dorsal surface of the apex and lingual body in Bison bonasus hybrid differ from the dense arrangement of these papillae on lateral areas of the lingual body in cattle and European bison. Significant diversities were also noticed on the ventral surface of the apex. In Bison bonasus hybrid observed V-pattern distribution of Fu papillae, whereas these papillae in cattle and European bison were arranged marginally. In turn, a similar dispersed arrangement of $\mathrm{Fu}$ papillae in all examined ruminants was observed on the dorsal surface of the medial and posterior part of lingual prominence and its lateral surfaces [27].

The aim of the present study was a detailed analysis of 3D models presented microstructure of Fu papillae in different areas of the tongue in three mentioned earlier species of ruminants with the histomorphometric data of the papillae. We also want proof if three-dimensional analysis will be an efficient tool in identifying many microstructures of lingual papillae as spatial relation between papillae and surrounded epithelium, the shape of internal skeleton, detailed arrangement, and a number of taste buds in Fu papillae, which will be helpful in normal, pathological, or clinical assessments.

\section{Results}

Cross-sections of Fu papillae and 3D models with distribution of taste buds taken from particular parts of studied ruminants tongues are presented in Fig. 1.1 - 6.3. Figure 7 presents 3D models of connective tissue cores (CTCs) of Fu papillae. Table 1 contains the number and density of $\mathrm{Fu}$ papillae and taste buds. The values of the height and diameter of $\mathrm{Fu}$ papillae and connective tissue cores (CTCs) are present in Tables 2 and 3, respectively. Table 4 contains data of the height of stratified squamous epithelium on Fu papillae and the interpapillary stratified epithelium, while in Table 5 are presented the diameters of taste buds from particular parts of tongues.

\section{Dorsal surface of the apex of the tongue}

In cattle, $13 \mathrm{Fu}$ papillae with the density of 0.5 papilla per $1 \mathrm{~cm}^{2}$ were spread regularly between filiform papillae on the dorsal surface of the apex (Table 1). The Fu papillae were round in outline with convex, smooth surface, and the diameter was $1070 \mu \mathrm{m}$ on average (Table 2). The mean height of these papillae was ca. $1980.7 \mu \mathrm{m}$ (Table 2, Fig. 1.1), and concerning mucosal epithelium, these papillae protruded on $413.4 \mu \mathrm{m}$ (Table 4, Fig. 8A). Based on measurements of diameter in basal, medial, and dorsal parts of internal connective tissue of $\mathrm{Fu}$ papillae, 


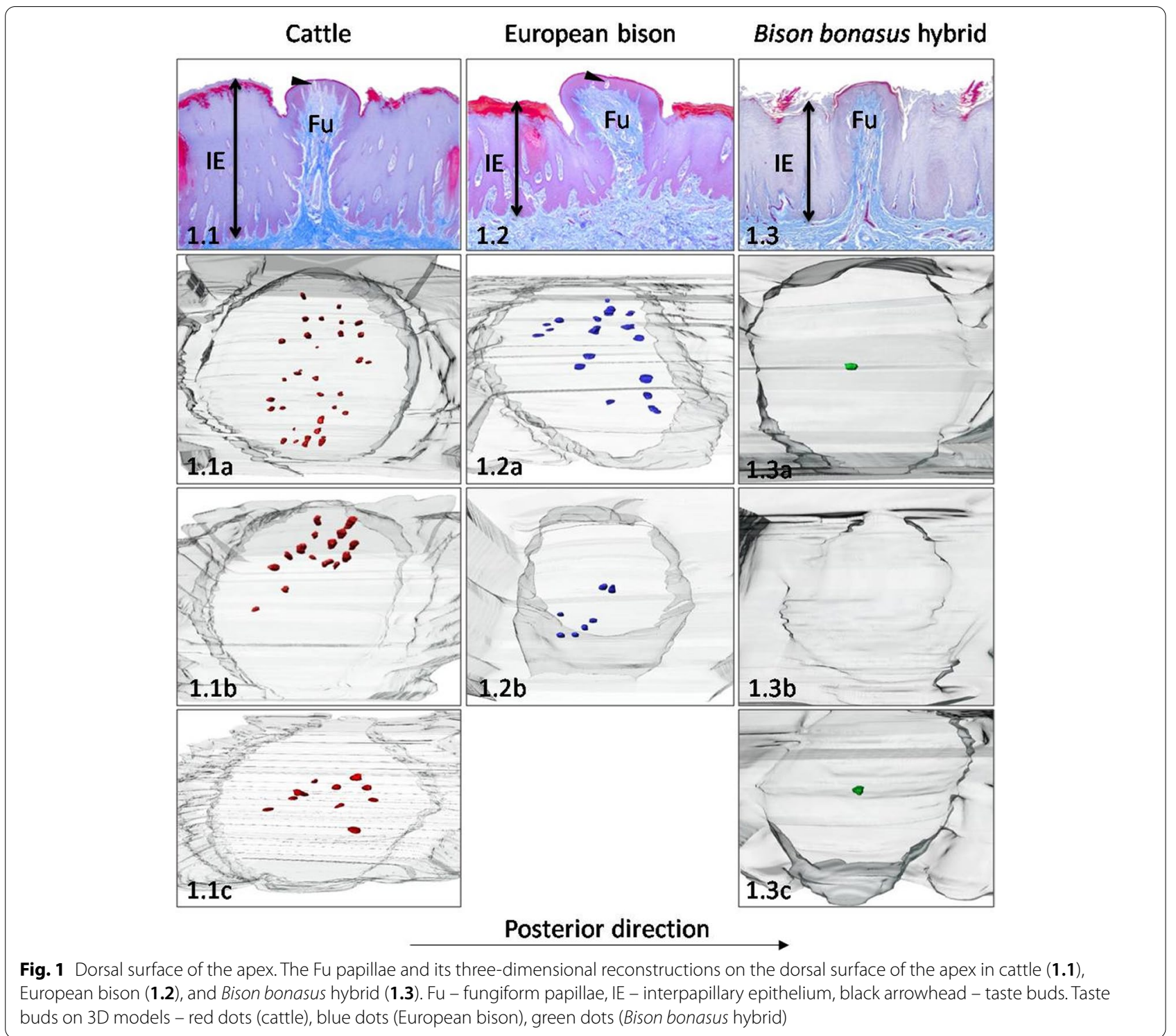

the shape of CTC was described as balloon-like (Table 3, Figs. 1.1, 7A and 8B). The height of the stratified epithelium on Fu papillae reached $115.4 \mu \mathrm{m}$, while its keratinized layer represented $15.5 \%$ of the epithelium thickness (Table 4, Fig. 8C). Three studied 3D models of Fu papillae showed different patterns of distribution of taste buds on the dorsal surface of papillae. Taste buds were arranged in the median part of the papilla in the form of strip located perpendicularly to the median line of the tongue (Fig. 1.1a). On the other hand, taste buds formed clusters were positioned centrally or on the left side of Fu papillae (Fig. 1.1b, 1.1c). The average number of taste buds was 23 , while the density reached 20 taste buds $/ \mathrm{mm}^{2}$ of papilla surface (Table 1). Moreover, the average diameter of taste buds ranged between $29.9 \mu \mathrm{m}-62.9 \mu \mathrm{m}$ (Table 5).
In European bison, $\mathrm{Fu}$ papillae were like cattle, spread evenly among filiform papillae, but its number and density reached $31,0.4$ papilla $/ \mathrm{cm}^{2}$, respectively (Table 1). The elliptical in outline papillae have a convex and smooth dorsal surface with diameter of $953.8 \mu \mathrm{m}$ (Fig. 1.2, Table 2). The mean height of Fu papillae reached $1442.2 \mu \mathrm{m}$ (Table 2), whereas the protrusion of Fu papillae over the surface of lingual mucosa was $390.5 \mu \mathrm{m}$ (Table 4, Fig. 8A). The CTC with a broad dorsal part had a balloon-like shape (Table 3, Figs. 1.2, 7A and 8B). The height of stratified squamous epithelium was $140.8 \mu \mathrm{m}$, and its keratinized layer was $14.7 \%$ of its thickness (Table 4, Fig. 8C). The 3D models of Fu papillae in European bison presented in average 12 taste buds arranged in clusters on the right or left part of the papilla (Table 1, 
Table 1 The number and density of fungiform papillae (Fu) and its taste buds on cattle, European bison, and Bison bonasus hybrid tongue

\begin{tabular}{|c|c|c|c|c|c|c|}
\hline & Cattle & & European bison & & Bison bonasus hyk & \\
\hline \multirow[t]{2}{*}{ Parts of tongue } & Number of Fu & $\begin{array}{l}\text { Density of } \\
\text { Fu per } 1 \mathrm{~cm}^{2}\end{array}$ & Number of Fu & $\begin{array}{l}\text { Density of } \\
\text { Fu per } 1 \mathrm{~cm}^{2}\end{array}$ & Number of Fu & $\begin{array}{l}\text { Density } \\
\text { of Fu per } \\
1 \mathrm{~cm}^{2}\end{array}$ \\
\hline & $\begin{array}{l}\text { Number of taste } \\
\text { buds per papilla }\end{array}$ & $\begin{array}{l}\text { Density of } \\
\text { taste buds } \\
\text { per } 1 \mathrm{~mm}^{2}\end{array}$ & $\begin{array}{l}\text { Number of taste } \\
\text { buds per papilla }\end{array}$ & $\begin{array}{l}\text { Density of } \\
\text { taste buds } \\
\text { per } 1 \mathrm{~mm}^{2}\end{array}$ & $\begin{array}{l}\text { Number of taste } \\
\text { buds per papilla }\end{array}$ & $\begin{array}{l}\text { Density of } \\
\text { taste buds } \\
\text { per } 1 \mathrm{~mm}^{2}\end{array}$ \\
\hline \multirow{2}{*}{$\begin{array}{l}\text { Dorsal surface of the apex } \\
\text { X (Min - Max) }\end{array}$} & 13 & 0.5 & 31 & 0.4 & 222 & 9 \\
\hline & $23(10-31)$ & 20 & $12(7-17)$ & 12 & $1(0-1)$ & 3 \\
\hline \multirow{2}{*}{$\begin{array}{l}\text { Ventral surface of the apex } \\
\text { X (Min - Max) }\end{array}$} & 47 & 7.8 & 50 & 2.6 & 220 & 20 \\
\hline & $64(47-82)$ & 41 & $18(6-30)$ & 20 & $20(10-30)$ & 21 \\
\hline \multirow{2}{*}{$\begin{array}{l}\text { Dorsal surface of the lingual body } \\
\text { X (Min - Max) }\end{array}$} & 35 & 0.8 & 32 & 1 & 118 & 3 \\
\hline & $41(20-55)$ & 22 & $10(5-13)$ & 10 & $3(3-4)$ & 5 \\
\hline \multirow{2}{*}{$\begin{array}{l}\text { Dorsal surface of medial part of torus } \\
\text { X (Min - Max) }\end{array}$} & 15 & 0.5 & 23 & 0.8 & 15 & 0.6 \\
\hline & $13(4-22)$ & 5 & $4(3-4)$ & 2 & $13(5-20)$ & 11 \\
\hline \multirow{2}{*}{$\begin{array}{l}\text { Dorsal surface of posterior part of torus } \\
\text { X (Min - Max) }\end{array}$} & 30 & 0.9 & 20 & 0.9 & 46 & 2.7 \\
\hline & $37(31-43)$ & 24 & $14(4-24)$ & 4 & $13(8-18)$ & 11 \\
\hline \multirow{2}{*}{$\begin{array}{l}\text { Lateral surfaces of torus } \\
\text { X (Min - Max) }\end{array}$} & 45 & 1.0 & 46 & 1.1 & 38 & 1.2 \\
\hline & $17(4-29)$ & 16 & $14(6-21)$ & 18 & $23(16-29)$ & 19 \\
\hline
\end{tabular}

Table 2 Histomorphometry of Fu papillae on cattle, European bison, and Bison bonasus hybrid tongue

\begin{tabular}{|c|c|c|c|c|}
\hline Parts of tongue & Fungiform papillae & Cattle & European bison & Bison bonasus hybrid \\
\hline \multirow{2}{*}{$\begin{array}{l}\text { Dorsal surface of the apex } \\
\text { X (Min - Max) }\end{array}$} & Height of the papilla ( $\mu m)$ & $1980.7(1756.4-2354.8)$ & $\mathbf{1 4 4 2 . 2}(1219.3-1649.4)$ & $1326.2(1200-1406.4)$ \\
\hline & Diameter of the papilla $(\mu \mathrm{m})$ & $1070.2(759.7-1322.5)$ & $953.8(844.4-1032.5)$ & $\mathbf{6 7 3 . 0}(554.8-722.6)$ \\
\hline \multirow{2}{*}{$\begin{array}{l}\text { Ventral surface of the apex } \\
\text { X (Min - Max) }\end{array}$} & Height of the papilla ( $\mu m)$ & $1358.6(1219.3-1451.6)$ & $1016.4(754.8-1205.1)$ & $1104(673.1-1406.4)$ \\
\hline & Diameter of the papilla $(\mu \mathrm{m})$ & $1056.2(903.2-1131.7)$ & $990.4(522.6-1212.9)$ & $664.9(490.3-844.1)$ \\
\hline \multirow{2}{*}{$\begin{array}{l}\text { Dorsal surface of lingual body } \\
\text { X (Min - Max) }\end{array}$} & Height of the papilla ( $\mu m)$ & $1343.9(1187.1-1438.7)$ & $1508.2(1187.0-1438.7)$ & $1322.7(1269.2-1380.6)$ \\
\hline & Diameter of the papilla $(\mu \mathrm{m})$ & $1173.1(909.6-1348.3)$ & $1102.5(909.6-1348.3)$ & $828.9(687.9-909.6)$ \\
\hline \multirow{2}{*}{$\begin{array}{l}\text { Dorsal surface of medial part of torus } \\
\text { X (Min - Max) }\end{array}$} & Height of the papilla ( $\mu \mathrm{m})$ & $1319.8(1149.3-1435.0)$ & $1165.8(612.9-1435.2)$ & $2060.1(1902.2-2214.9)$ \\
\hline & Diameter of the papilla $(\mu \mathrm{m})$ & $1865.6(1361.3-2155.8)$ & $\mathbf{1 6 2 8 . 0}(1167.7-2174.2)$ & $1357.7(1103.9-1593.6)$ \\
\hline \multirow{2}{*}{$\begin{array}{l}\text { Dorsal surface of posterior part of torus } \\
\text { X (Min - Max) }\end{array}$} & Height of the papilla ( $\mu m)$ & $1402.1(1013.0-1629.8)$ & $1397.4(1032.4-1717.9)$ & $1221.5(1032.4-1425.8)$ \\
\hline & Diameter of the papilla $(\mu \mathrm{m})$ & $1095.7(954.2-1313.7)$ & $\mathbf{1 6 7 5 . 4}(1134.6-1883.1)$ & $895.0(792.2-1006.4)$ \\
\hline \multirow{2}{*}{$\begin{array}{l}\text { Lateral surfaces of torus } \\
\text { X (Min - Max) }\end{array}$} & Height of the papilla ( $\mu m)$ & $1314.0(1078.6-1649.3)$ & $1589.0(1103.2-1717.9)$ & $1601.9(1361.3-1771.2)$ \\
\hline & Diameter of the papilla $(\mu \mathrm{m})$ & $1071.7(594.8-1461.0)$ & $655.6(564.1-1461.0)$ & $\mathbf{9 6 4 . 0}(764.7-1214.3)$ \\
\hline
\end{tabular}

Fig. 1.2a, 1.2b). The density of taste buds on the dorsal surface of Fu papillae was 12 taste buds $/ \mathrm{mm}^{2}$ (Table 1), while the mean diameter of taste buds reached $47.9 \mu \mathrm{m}$ (Table 5).

The Bison bonasus hybrid has numerous i.e., 222 evenly spread Fu papillae on the dorsal surface apex (Table 1). Their density reached nine papillae $/ \mathrm{cm}^{2}$ (Table 1 ). These rounded in outline papillae were characterized by flat and smooth surfaces with the mean values of its diameter ranged between $554 \mu \mathrm{m}$ and $722 \mu \mathrm{m}$ (Table 2, Fig. 1.3). The difference between the height of Fu papillae $-1326.2 \mu \mathrm{m}$, and the height of interpapillary stratified epithelium - $1166.2 \mu \mathrm{m}$ i.e. the value of the papillary protrusion equals $160 \mu \mathrm{m}$ (Tables 2 and 4, Fig. 8A). Diameters of Fu papillae CTCs indicated the columnar-like shape of this internal skeleton of Fu papillae. (Table 3, Figs. 1.3, 7B and 8B). The thickness of the epithelium covering Fu papillae was $119.7 \mu \mathrm{m}$ on average, whereas its keratinized layer amount to $16 \%$ of the epithelium thickness (Table 4, Fig. 8C). In two 3D models of these papillae, only a single taste bud of the mean diameter $32.5 \mu \mathrm{m}$ were positioned centrally on surface of papilla (Table 5, Fig. 1.3a, 1.3c). In turn, in the third prepared model observed a lack of taste buds in dorsal epithelium 
Table 3 Diameters of CTCs in dorsal, medial and basal part of Fu papillae on cattle, European bison, and Bison bonasus hybrid tongue

\begin{tabular}{|c|c|c|c|c|}
\hline Parts of tongue & Diameter of CTC & Cattle & European bison & Bison bonasus hybrid \\
\hline \multirow{3}{*}{$\begin{array}{l}\text { Dorsal surface of the apex } \\
\text { X (Min - Max) }\end{array}$} & Dorsal part & $637.1(445.2-851.6)$ & $635.9(559.2-743.4)$ & $367.9(270.9-451.6)$ \\
\hline & Medial part & $358.9(200-438.7)$ & $402.4(322,4-447.4)$ & $334.8(232.2-458.1)$ \\
\hline & Basal part & $1013.5(506.4-1303.2)$ & $715.0(638.7-864.5)$ & $659.2(425.8-870.9)$ \\
\hline \multirow{3}{*}{$\begin{array}{l}\text { Ventral surface of the apex } \\
\text { X (Min - Max) }\end{array}$} & Dorsal part & $923.8(677.5-1147.7)$ & $\mathbf{5 7 1 . 4}(331.2-832.3)$ & $481.3(327.8-600.8)$ \\
\hline & Medial part & $620.1(374.2-862.3)$ & $518.3(383.2-766.2)$ & $416.2(339.9-483.9)$ \\
\hline & Basal part & $944.1(793.5-1090.3)$ & $\mathbf{8 0 2 . 5}(519.4-935.5)$ & $682.3(522.6-883.1)$ \\
\hline \multirow{3}{*}{$\begin{array}{l}\text { Dorsal surface of the lingual body } \\
\text { X (Min - Max) }\end{array}$} & Dorsal part & $700.4(599.9-870.9)$ & $476.5(387.1-664.5)$ & $603.9(558.4-662.4)$ \\
\hline & Medial part & $484.6(400-625.8)$ & $451.9(290.3-611.8)$ & $462.4(337.6-513)$ \\
\hline & Basal part & $1028.9(904.4-1212.9)$ & $900.1(904.4-1212.9)$ & $768.5(643.3-870.9)$ \\
\hline \multirow{3}{*}{$\begin{array}{l}\text { Dorsal surface of medial part of torus } \\
\text { X (Min - Max) }\end{array}$} & Dorsal part & $1404.8(1162.4-1662.4)$ & $818.1(583.4-1329)$ & $997.3(724.4-1188,2)$ \\
\hline & Medial part & $1698.1(1305.2-1909.1)$ & $929.3(524.6-1554.8)$ & $687.6(429.7-831.1)$ \\
\hline & Basal part & $1898.5(1303.6-2207.8)$ & $1402.3(1174.2-2180.6)$ & $1277.9(1038.9-1428.6)$ \\
\hline \multirow{3}{*}{$\begin{array}{l}\text { Doral surface of posterior part of torus } \\
\text { X (Min - Max) }\end{array}$} & Dorsal part & $881.9(629.9-1071.7)$ & $1439.4(910.3-1764.8)$ & $662.2(516.5-807.9)$ \\
\hline & Medial part & $649.9(389.8-831.2)$ & $1456.2(967.3-1826.9)$ & $558.1(398.7-642.5)$ \\
\hline & Basal part & $1265.8(830.9-1548.9)$ & $1769.2(1346.1-2097.4)$ & $1067.4(883.8-1181.8)$ \\
\hline \multirow{3}{*}{$\begin{array}{l}\text { Lateral surfaces of torus } \\
\text { X (Min - Max) }\end{array}$} & Dorsal part & $574.6(290.4-961.6)$ & $381.8(294.3-474.1)$ & $708.9(483.8-929.5)$ \\
\hline & Medial part & $633.2(407.3-787.1)$ & $389.8(193.5-551.9)$ & $\mathbf{5 7 0 . 6}(367.8-801.3)$ \\
\hline & Basal part & $1056.6(712.4-1467.5)$ & $665.9(583.3-1109.7)$ & $1063.7(767.7-1400)$ \\
\hline
\end{tabular}

(Fig. 1.3b). The mean density of taste buds was three taste buds $/ \mathrm{mm}^{2}$ (Table 1 ).

\section{Ventral surface of the apex of the tongue}

In cattle, $47 \mathrm{Fu}$ papillae appeared symmetrically on lateral borders of the ventral surface of the tongue, while the mean density was 7.8 papillae $/ \mathrm{cm}^{2}$ (Table 1 ). Convex $\mathrm{Fu}$ papillae with an average diameter of $1056.2 \mu \mathrm{m}$ were round in outline (Table 2, Fig. 2.1). Fu papillae and interpapillary epithelium height were $1358.6 \mu \mathrm{m}$, and $1016 \mu \mathrm{m}$, respectively (Tables 2,4 ). Thus, the average protrusion of these papillae was $342.2 \mu \mathrm{m}$ (Fig. 8A). The shape of CTC of Fu papillae presented in Fig. 7A, resembled a balloon (Table 3, Figs. 2.1, 8B). The epithelium on the Fu papillae was $108.2 \mu \mathrm{m}$ in thickness with the keratinized layer, which was $10 \%$ of its entire thickness (Table 4, Fig. 8C). In cattle, the 64 taste buds on average, were evenly arranged posteriorly or on the whole surface of the dorsal part of Fu papillae (Table 1, Fig. 2.1a, 2.1b). The density of taste buds in these papillae reached 41 taste buds $/ \mathrm{mm}^{2}$, while the mean diameter of taste buds was $39.5 \mu \mathrm{m}$ (Tables 1 and 5).

In European bison, $50 \mathrm{Fu}$ papillae covered both left and right marginal areas of the ventral surface of the tongue (Table 1). The density of these elliptical or rounded papillae was 2.6 papillae $/ \mathrm{cm}^{2}$ (Table 1, Fig. 2.2). Generally, Fu papillae had flat, smooth dorsal surface, and the diameter ranged between $552 \mu \mathrm{m}$ and $1212 \mu \mathrm{m}$ (Table 2, Fig. 2.2). The difference between the height of Fu papilla and the interpapillary epithelium equals $245.6 \mu \mathrm{m}$, which was the mean value of papillary protrusion (Tables 2 and 4, Fig. 8A). Obtained diameter of 3D models of CTC revealed its columnar-like shape (Table 3, Figs. 2.2, 7B and $8 \mathrm{~B})$. The stratified squamous epithelium was on average $139.5 \mu \mathrm{m}$ high, while its keratinised layer accounted $10.6 \%$ of the total epithelium thickness (Table 4, Fig. 8C). The taste buds in European bison were arranged anteriorly and near the right border of the dorsal surface of $\mathrm{Fu}$ papillae (Fig. 2.2a, 2.2b). Their average number on two 3D models was 18 taste buds, while their estimated density reached 20 taste buds $/ \mathrm{mm}^{2}$ (Table 1 ). The average diameter of taste buds was $41.7 \mu \mathrm{m}$ (Table 5).

A total of $220 \mathrm{Fu}$ papillae were arranged in a V-letter on the Bison bonasus hybrid tongue (Table 1). Additionally, two types of Fu papillae were observed. Bigger Fu papillae created a border between smooth area and area covered by lingual papillae, while smaller Fu papillae were spread between filiform papillae. Its density reached $20 \mathrm{Fu}$ papillae $/ \mathrm{cm}^{2}$ (Table 1). Fu papillae were elliptical or round in outline with a mean diameter of $664.9 \mu \mathrm{m}$ (Table 2, Fig. 2.3). Its dorsal surface was convex and smooth (Fig. 2.3). The height of Fu papillae, interpapillary stratified epithelium, and the papillary protrusion reached $1104 \mu \mathrm{m}, 930.1 \mu \mathrm{m}$, and $173.9 \mu \mathrm{m}$, respectively (Tables 2 and 4, Fig. 8A). There were observed columnar-like shape CTCs (Table 3, Figs. 2.1, 7B and 8B). The thickness of the epithelium on $\mathrm{Fu}$ papillae was $96.9 \mu \mathrm{m}$, of which $9.5 \%$ was the keratinized layer (Table 4, Fig. 8C). The patterns of 20 taste buds in average in Bison bonasus hybrid were arranged posteriorly in a crescent shape and on the 
Table 4 The histomorphometry of interpapillary stratified epithelium and stratified squamous epithelium with keratinized layer on the dorsal surface of Fu papillae in cattle, European bison, and Bison bonasus hybrid

\begin{tabular}{|c|c|c|c|c|}
\hline Parts of tongue & Fungiform papillae & Cattle & European bison & Bison bonasus hybrid \\
\hline \multirow[t]{3}{*}{$\begin{array}{l}\text { Dorsal surface of the apex } \\
\text { X (Min - Max) }\end{array}$} & $\begin{array}{l}\text { Height of stratified squamous } \\
\text { epithelium }(\mu \mathrm{m})\end{array}$ & $115.4(13.0-232.6)$ & $140.8(56.7-286.9)$ & $119.7(47.6-217.3)$ \\
\hline & $\begin{array}{l}\text { Height of the keratinized layer of } \\
\text { the epithelium }[\mu \mathrm{m}]\end{array}$ & $17.9(10.8-32.1)$ & $20.8(11.5-63.5)$ & $19.2(5.8-40.3)$ \\
\hline & $\begin{array}{l}\text { Height of interpapillary epithelium } \\
(\mu \mathrm{m})\end{array}$ & $1567.3(1506.4-2341.9)$ & $1051.7(741.9-1253.9)$ & $1166.2(987.1-1316.1)$ \\
\hline \multirow[t]{3}{*}{$\begin{array}{l}\text { Ventral surface of the apex } \\
\text { X (Min - Max) }\end{array}$} & $\begin{array}{l}\text { Height of stratified squamous } \\
\text { epithelium }(\mu \mathrm{m})\end{array}$ & $108.2(48.4-214.5)$ & $139.5(65.3-264.9)$ & $96.9(31.6-265.5)$ \\
\hline & $\begin{array}{l}\text { Height of keratinized layer of } \\
\text { epithelium }(\mu \mathrm{m})\end{array}$ & $11.1(4.8-22.4)$ & $14.9(5.1-33.9)$ & $9.2(3.6-27.6)$ \\
\hline & $\begin{array}{l}\text { Height of interpapillary epithelium } \\
(\mu \mathrm{m})\end{array}$ & $1016.4(726.5-1378.0)$ & $770.8(309.6-1149.3)$ & $930.1(593.5-1167.7)$ \\
\hline \multirow[t]{3}{*}{$\begin{array}{l}\text { Dorsal surface of lingual body } \\
\text { X (Min - Max) }\end{array}$} & $\begin{array}{l}\text { Height of stratified squamous } \\
\text { epithelium }(\mu \mathrm{m})\end{array}$ & $122.3(40.4-304.3)$ & $166.5(67.7-276.9)$ & $118.6(41.3-188.4)$ \\
\hline & $\begin{array}{l}\text { Height of keratinized layer of } \\
\text { epithelium }(\mu \mathrm{m})\end{array}$ & $16.2(6.6-30.4)$ & $20.6(9.6-32.6)$ & $19.0(8.2-42.2)$ \\
\hline & $\begin{array}{l}\text { Height of interpapillary epithelium } \\
(\mu \mathrm{m})\end{array}$ & $1096.9(519.2-1374.2)$ & $1067.1(519.2-1372.2)$ & $1221.5(1154.8-1296.8)$ \\
\hline \multirow{3}{*}{$\begin{array}{l}\text { Dorsal surface of medial part of } \\
\text { torus } \\
\text { X (Min - Max) }\end{array}$} & $\begin{array}{l}\text { Height of stratified squamous } \\
\text { epithelium }(\mu \mathrm{m})\end{array}$ & $143.2(21.9-302.2)$ & $150.6(64.5-265.2)$ & $121.9(31.9-259.9)$ \\
\hline & $\begin{array}{l}\text { Height of keratinized layer of } \\
\text { epithelium }(\mu \mathrm{m})\end{array}$ & $29.2(15.3-83.6)$ & $37.1(21.0-65.8)$ & $35.8(12.9-98.1)$ \\
\hline & $\begin{array}{l}\text { Height of interpapillary epithelium } \\
(\mu \mathrm{m})\end{array}$ & $1006.9(675.3-1432.2)$ & $838.8(296.7-1432.2)$ & $1897.8(1612.9-2148.4)$ \\
\hline \multirow{3}{*}{$\begin{array}{l}\text { Dorsal surface of posterior part of } \\
\text { torus } \\
\text { X (Min - Max) }\end{array}$} & $\begin{array}{l}\text { Height of stratified squamous } \\
\text { epithelium }(\mu \mathrm{m})\end{array}$ & $112.9(47.4-193.1)$ & $129.5(52.2-259.9)$ & $113.3(31.2-211.2)$ \\
\hline & $\begin{array}{l}\text { Height of keratinized layer of } \\
\text { epithelium }(\mu \mathrm{m})\end{array}$ & $17.2(6.7-39.2)$ & $19.2(9.8-37.4)$ & $16.8(8.1-32.1)$ \\
\hline & $\begin{array}{l}\text { Height of interpapillary epithelium } \\
(\mu \mathrm{m})\end{array}$ & $470.0(331.2-640.5)$ & $680.7(397.4-948.7)$ & $944.4(616.9-1206.3)$ \\
\hline \multirow[t]{3}{*}{$\begin{array}{l}\text { Lateral surfaces of torus } \\
\text { X (Min - Max) }\end{array}$} & $\begin{array}{l}\text { Height of stratified squamous } \\
\text { epithelium }(\mu \mathrm{m})\end{array}$ & $147.1(56.8-361.9)$ & $120.9(50.9-236.9)$ & $121.2(34.3-216.9)$ \\
\hline & $\begin{array}{l}\text { Height of keratinized layer of } \\
\text { epithelium }(\mu \mathrm{m})\end{array}$ & $31.5(14.8-74.3)$ & $20.9(9.4-68.1)$ & $17.7(5.8-41.9)$ \\
\hline & $\begin{array}{l}\text { Height of interpapillary epithelium } \\
(\mu \mathrm{m})\end{array}$ & $1205.3(864.5-1577.9)$ & $1147.8(864.5-1423.0)$ & $\mathbf{1 4 0 8 . 9}(1181.8-1535.5)$ \\
\hline
\end{tabular}

Table 5 The diameter of taste buds in cattle, European bison, and Bison bonasus hybrid

\begin{tabular}{|c|c|c|c|}
\hline & Cattle & European bison & Bison bonasus hybrid \\
\hline Parts of tongue & $\begin{array}{l}\text { Diameter of taste buds }(\mu \mathrm{m}) \\
\mathbf{X}(\text { Min - Max })\end{array}$ & $\begin{array}{l}\text { Diameter of taste buds }(\mu \mathrm{m}) \\
\mathbf{X}(\text { Min - Max) }\end{array}$ & $\begin{array}{l}\text { Diameter of taste buds }(\mu \mathrm{m}) \\
\mathbf{X}(\text { Min - Max) }\end{array}$ \\
\hline Dorsal surface of the apex & $40.9(29.9-62.9)$ & $47.9(38.7-57.5)$ & $32.5(30.2-32.5)$ \\
\hline Ventral surface of the apex & $39.5(31.0-51.9)$ & $41.7(29.6-52.5)$ & $42.6(29.6-63.9)$ \\
\hline Dorsal surface of the lingual body & $41.2(30.2-55.6)$ & $42.4(29.0-54.8)$ & $45.2(39.5-56.4)$ \\
\hline Dorsal surface of medial part of torus & $41.1(37.1-45.7)$ & $45.1(30.6-58.0)$ & $42.2(25.9-56.5)$ \\
\hline Dorsal surface of posterior part of torus & $40.6(30.1-49.4)$ & $42.9(29.9-56.0)$ & $36.5(25.8-60.1)$ \\
\hline Lateral surfaces of torus & $44.8(32.2-63.0)$ & $38.8(23.8-56.1)$ & $36.9(24.2-50.3)$ \\
\hline
\end{tabular}




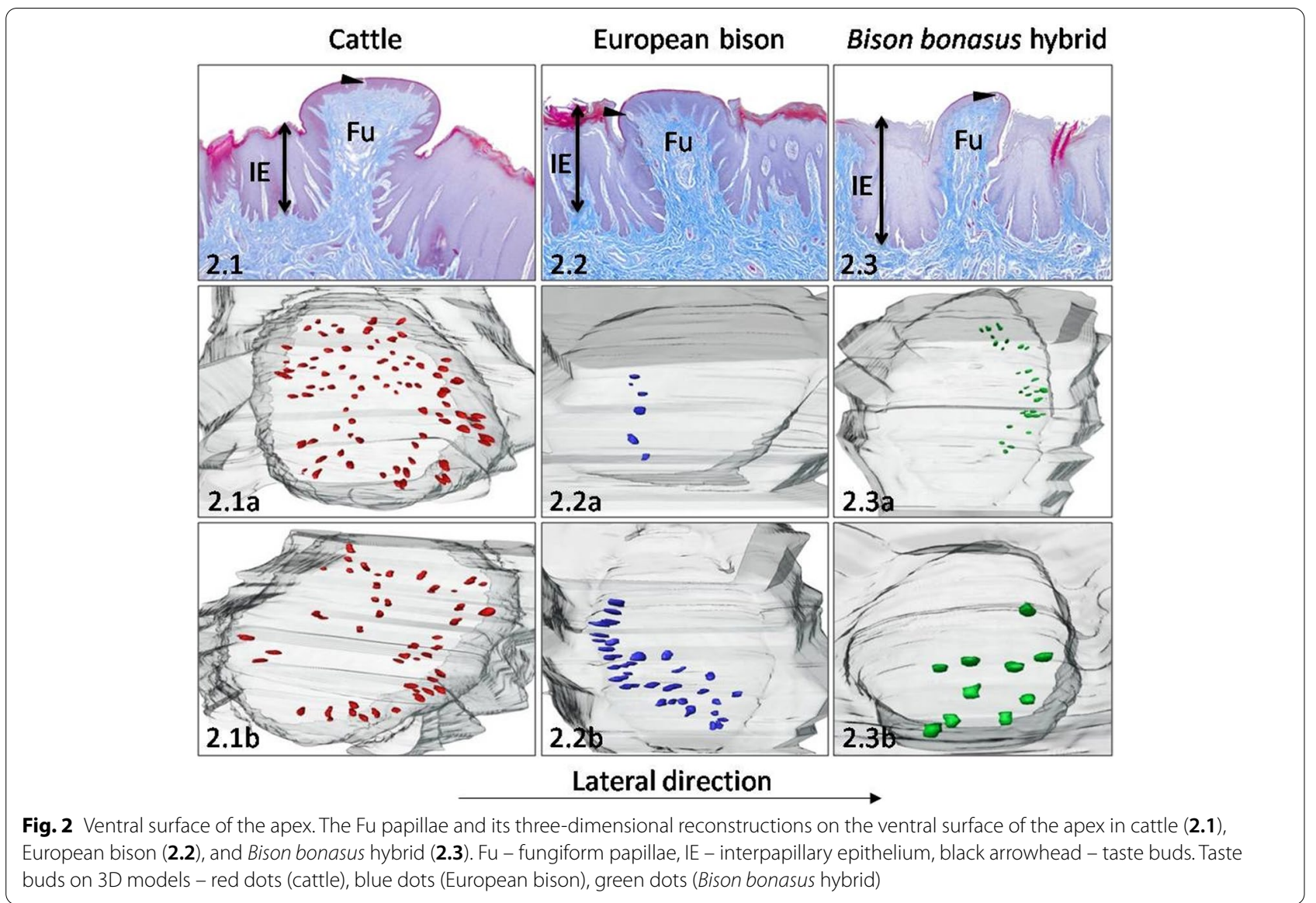

right part of the dorsal surface of Fu papillae (Table 1, Figs. 2.3a, 2.3b). The estimated density of taste buds was 21 taste buds $/ \mathrm{mm}^{2}$ (Table 1 ). In turn, their mean diameter reached $42.6 \mu \mathrm{m}$ (Table 5).

\section{Dorsal surface of the lingual body}

In cattle and European bison, Fu papillae were observed on the lateral areas of the lingual body. In contrast, in the Bison bonasus hybrid Fu papillae were distributed on the whole dorsal surface of the lingual body.

In cattle observed $35 \mathrm{Fu}$ papillae with the density of 0.8 papilla/ $\mathrm{cm}^{2}$ (Table 1). Round or elliptical Fu papillae in outline with convex and smooth dorsal surface was $1173.1 \mu \mathrm{m}$ in diameter (Table 2, Fig. 3.1). The Fu papillae height was $1343.9 \mu \mathrm{m}$, while the interpapillary epithelium - $1096.9 \mu \mathrm{m}$, so the papillary protrusion equals $247 \mu \mathrm{m}$ (Tables 2, 4, Fig. 8A). The diameters of CTC characterized the balloon-like shape visible in Fig. 7A (Table 3, Figs. 3.1 amd $8 \mathrm{~B}$ ). The thickness of the epithelium on $\mathrm{Fu}$ papillae in this area of tongue was $122.3 \mu \mathrm{m}$ with the keratinized layer, which made up $13.2 \%$ of the entire epithelium thickness. (Table 4, Fig. 8C). The taste buds observed on 3D models of $\mathrm{Fu}$ papillae in cattle formed perpendicular or parallel strips concerning the median line of the tongue (Fig. 3.1a, 3.1b, 3.1c). Averaged number of taste buds was 41, while its estimated density reached 22 taste buds $/ \mathrm{mm}^{2}$ (Table 1 ). In turn, the measured diameter of taste buds ranged between $30.2 \mu \mathrm{m}-55.6 \mu \mathrm{m}$ (Table 5).

In European bison, the number and density of Fu papillae were 32 and 1 papilla/ $\mathrm{cm}^{2}$, respectively (Table 1 ). The Fu papillae with a mean diameter of $1102.5 \mu \mathrm{m}$ were round in outline with a convex and smooth dorsal surface (Table 2, Fig. 3.2). The average height of these papillae and the interpapillary epithelium reached 1508.2, and $1067.1 \mu \mathrm{m}$, respectively (Tables 2,4$)$. Thus, the protrusion of Fu papillae was $441.1 \mu \mathrm{m}$ (Fig. 8A). In regard to obtained dimensions, the CTC was columnar-like in shape (Table 3, Figs. 3.2, 7B and 8B). The thickness of the epithelium on $\mathrm{Fu}$ papillae was $166.5 \mu \mathrm{m}$, while the keratinized layer was $12 \%$ of its thickness (Table 4, Fig. 8C). In European bison, the arrangement of taste buds on the dorsal surface of the Fu papillae was different in each of the reconstructed papillae. On the first one, taste buds were arranged posteriorly in a crescent shape (Fig. 3.2a). On the second one, taste buds formed a centrally located strip arranged perpendicularly to the median line of the tongue (Fig. 3.2b). In turn, on the third one, a group of taste buds was located on the left part of the dorsal 


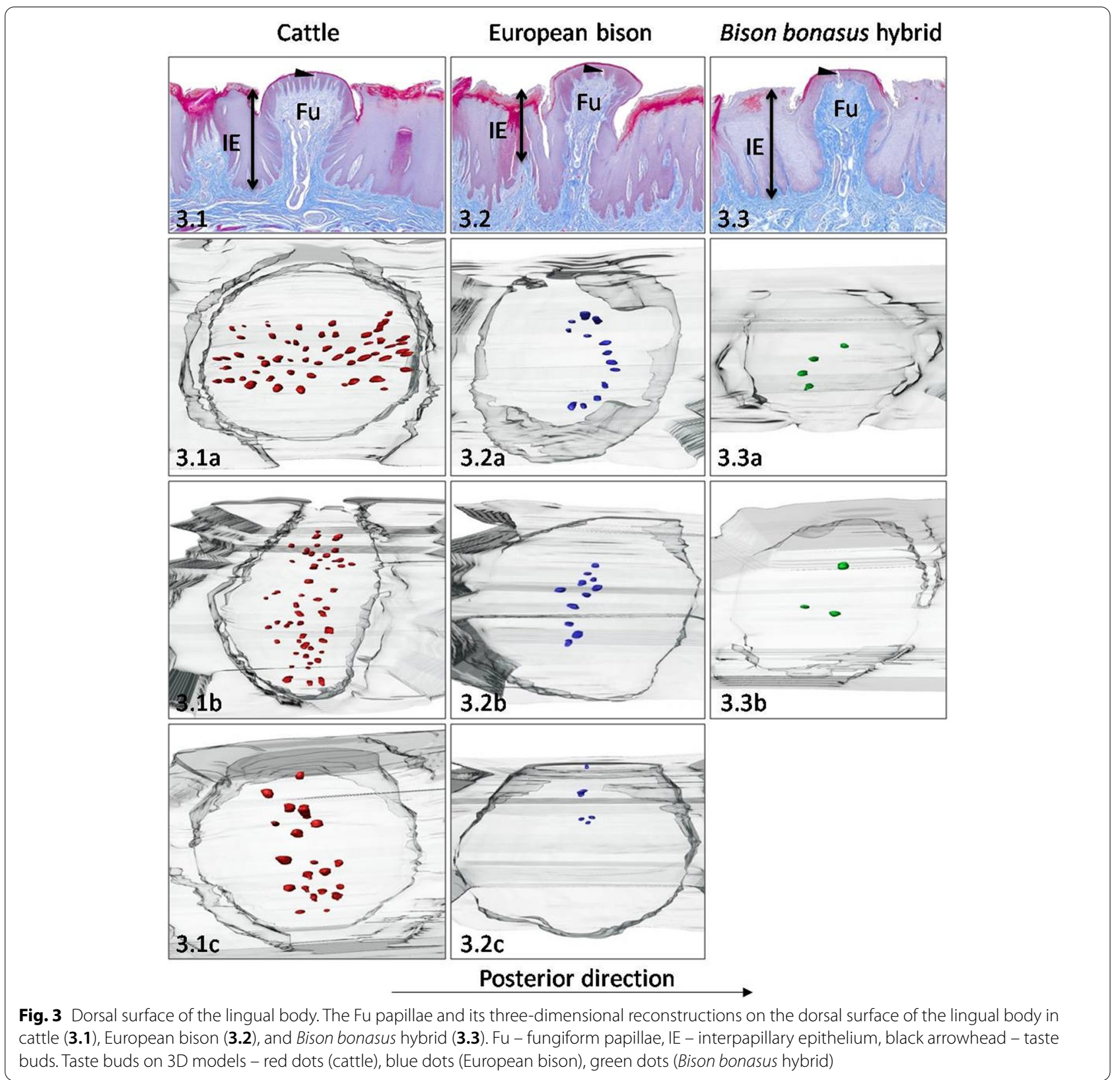

surface of Fu papilla (Fig. 3.2c). The average number of taste buds from these three models equals 10, as same as the estimated density - 10 taste buds $/ \mathrm{mm}^{2}$ (Table 1 ). Moreover, the measured diameter of taste buds was $42.4 \mu \mathrm{m}$ (Table 5).

In the Bison bonasus hybrid the number and density of $\mathrm{Fu}$ papillae reached 118 and $3 \mathrm{Fu}$ papillae $/ \mathrm{cm}^{2}$, respectively (Table 1 ). These papillae were round in outline with flat and smooth dorsal surface with the mean diameter of $828.9 \mu \mathrm{m}$ (Table 2, Fig. 3.3). Its average height ranged between $1269 \mu \mathrm{m}$ and $1380 \mu \mathrm{m}$ (Table 2). Thus, analysing the thickness of the interpapillary epithelium, the protrusion of $\mathrm{Fu}$ papillae with the value of $101.2 \mu \mathrm{m}$ were estimated (Table 4, Fig. $8 \mathrm{~A}$ ). The Fu papillae CTC on the hybrid's lingual body was characterized by a balloon-like shape (Table 3, Figs. 3.3, 7A and $8 \mathrm{~B})$. The mean value of the thickness of the epithelium covering $\mathrm{Fu}$ papillae was $118.6 \mu \mathrm{m}$, while the keratinized layer represented $16 \%$ of its thickness and was higher as in parental species (Table 4, Fig. 8C). In the Bison bonasus hybrid, two 3D models of Fu papillae had centrally arranged taste buds (Fig. 3.3a, 3.3b). The mean number of taste buds reached 3 , while their density was five taste buds $/ \mathrm{mm}^{2}$ of the papilla surface (Table 1). Measured and averaged diameter of taste buds was $45.2 \mu \mathrm{m}$ (Table 5). 


\section{Dorsal surface of the medial part of the torus}

On the torus in cattle, European bison and Bison bonasus hybrid $\mathrm{Fu}$ papillae were observed on the medial and posterior part of the dorsal surface and on its lateral surfaces.

In cattle on the dorsal surface of the torus observed 15 $\mathrm{Fu}$ papillae with a density of 0.5 papilla/ $\mathrm{cm}^{2}$ (Table 1 ). In outline, $\mathrm{Fu}$ papillae were elliptical with $1865.6 \mu \mathrm{m}$ in diameter, whereas their surface was flat and undulated (Table 2, Fig. 4.1). The height of $\mathrm{Fu}$ papillae, the interpapillary stratified epithelium, and papillary protrusion reached $1319.8 \mu \mathrm{m}, 1006.9 \mu \mathrm{m}$, and $312.9 \mu \mathrm{m}$, respectively (Tables 2 and 4, Fig. 8A). The diameters of CTC characterized the cone-like shape, visible on Fig. 7C (Table 3, Figs. 4.1 and $8 \mathrm{~B}$ ). In addition, Fu papillae were covered by $143.2 \mu \mathrm{m}$ of stratified squamous epithelium, in which the keratinized layer was $20 \%$ of its thickness (Table 4 , Fig. 8C). On 3D models of Fu papillae in cattle 13 taste buds formed clusters arranged posteriorly or centrally on the dorsal surface of Fu papillae (Table 1, Fig. 4.1a, 4.1b). The density of taste buds reached five taste buds $/ \mathrm{mm}^{2}$, while the diameter was $41.1 \mu \mathrm{m}$ (Tables 1 and 5).

In European bison, the number and density of pigmented $\mathrm{Fu}$ papillae were 23 and 0.8 papilla/ $\mathrm{cm}^{2}$, respectively (Table 1 ). The dorsal surface of the elliptical in outline Fu papillae was convex and irregular, while their diameter reached $1628 \mu \mathrm{m}$ (Table 2, Fig. 4.2). The comparison of the height of Fu papillae and interpapillary epithelium indicated the value of the papillary protrusion, which equals $327 \mu \mathrm{m}$ (Tables 2 and 4, Fig. 8A). In turn, measured diameters of CTC in the dorsal, medial and basal parts presented its cone-like shape (Table 3, Figs. 4.2, 7C and 8B). The thickness of stratified squamous epithelium on Fu papillae was $150.6 \mu \mathrm{m}$, while the keratinized layer represented $24.6 \%$ of the epithelium thickness (Table 4, Fig. 8C). In European bison only four taste buds were arranged on the left or central part of the dorsal surface of Fu papillae (Table 1, Fig. 4.2a, 4.2b). The estimated density of taste buds was two taste buds $/ \mathrm{mm}^{2}$, whereas its mean diameter equals $45.1 \mu \mathrm{m}$ (Tables 1 and 5).

The number and density of Fu papillae on the dorsal surface of the torus in the Bison bonasus hybrid reached 15 and 0.6 papilla $/ \mathrm{cm}^{2}$, respectively (Table 1 ). Fu papillae were round in outline with flat and smooth surface and had $1357.7 \mu \mathrm{m}$ in diameter (Table 2, Fig. 4.3). The $\mathrm{Fu}$ papillae were $2060.1 \mu \mathrm{m}$ in height, while the height

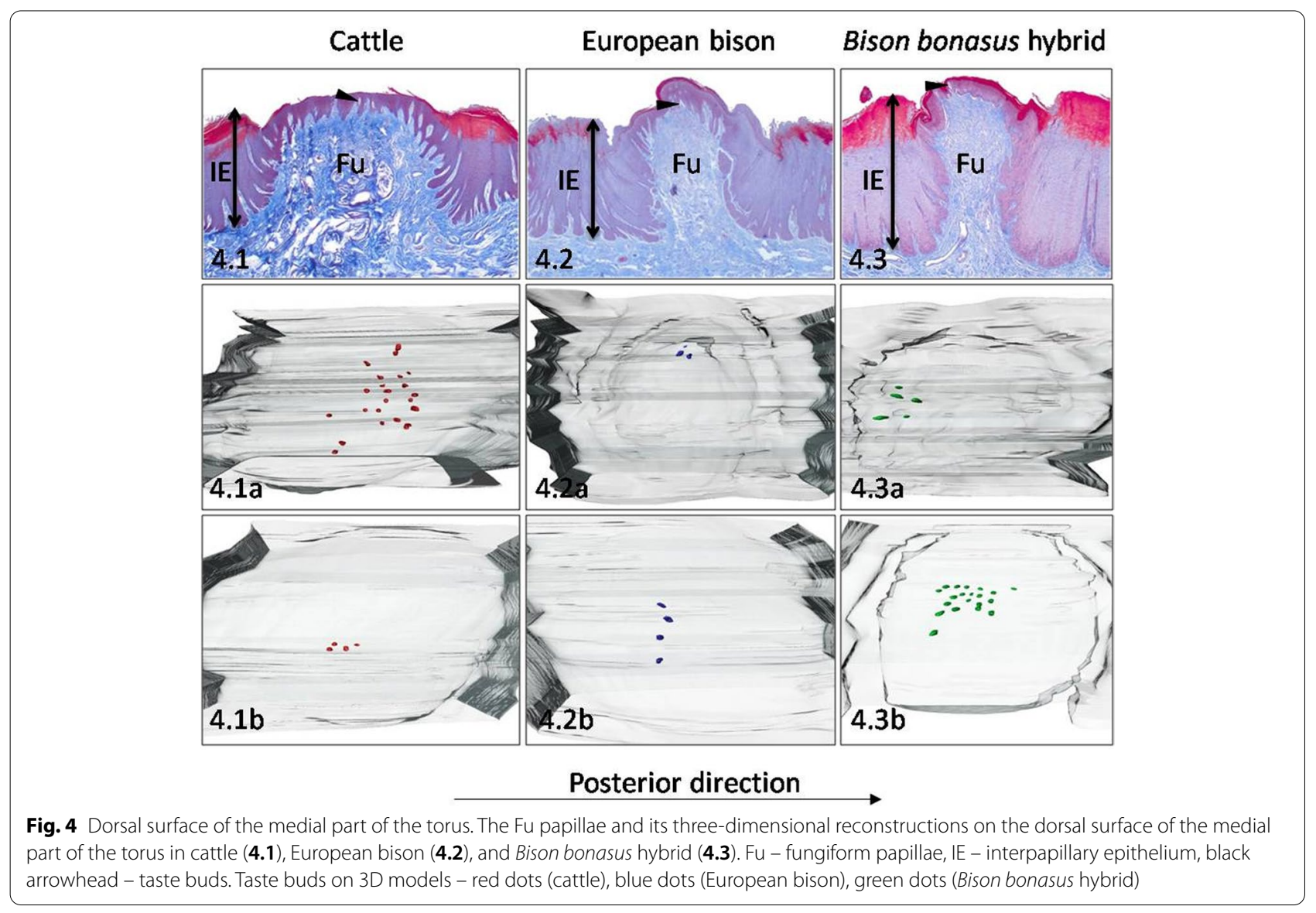


on the interpapillary stratified epithelium was $1897.8 \mu \mathrm{m}$ (Tables 2 and 4). Thus, the protrusion of the papillae equals $162.3 \mu \mathrm{m}$ (Fig. 8A). The CTC with a wide dorsal part had a balloon-like shape (Table 3, Figs. 4.3, 7A and 8B). The thickness of stratified squamous epithelium on the Fu papillae was $121.9 \mu \mathrm{m}$, of which $29 \%$ represented the keratinized layer, and at the same time it was the highest value among studied ruminants (Table 4, Fig. 8C). In Bison bonasus hybrid on two 3D models of Fu papillae, 13 taste buds arranged anteriorly were observed (Table 1 , Fig. 4.3a, 4.3b). The mean density of taste buds was 11 taste buds $/ \mathrm{mm}^{2}$, whereas its diameter was $42.2 \mu \mathrm{m}$ in average (Tables 1 and 5).

\section{Dorsal surface of the posterior part of the torus}

On the posterior part of cattle's torus observed $30 \mathrm{Fu}$ papillae, with a density of 0.9 papillae $/ \mathrm{cm}^{2}$ (Table 1 ). Fu papillae were rounded in outline, with a convex dorsal surface withan average diameter of $1095.7 \mu \mathrm{m}$ (Table 2, Fig. 5.1). Analysing the height of Fu papillae and the interpapillary epithelium, the papillary protrusion of $932.1 \mu \mathrm{m}$ was estimated (Tables 2 and 4, Fig. 8A). The CTC were the balloon-like shape (Table 3, Figs. 5.1, 7A and 8B). The average thickness of the stratified epithelium on the Fu papillae ranged between $47 \mu \mathrm{m}-193 \mu \mathrm{m}$, while the keratinized layer was $15 \%$ of the epithelium thickness (Table 4, Fig. 8C). The average number of 37 taste buds evenly spread on the dorsal surface of the Fu papillae in cattle present in Table 1, and Fig. 5.1a, 5.1b. Its estimated density reached 24 taste buds $/ \mathrm{mm}^{2}$, while its mean diameter ranged between $30.1 \mu \mathrm{m}-49.4 \mu \mathrm{m}$ (Tables 1, 5).

Like cattle, the estimated density of Fu papillae in European bison was 0.9 papilla $/ \mathrm{cm}^{2}$, but the number of these papillae was smaller as in cattle and reached 20 (Table 1). The dorsal part of rounded or elliptical in outline $\mathrm{Fu}$ papillae was also convex and smooth, while the diameter ranged between $1134 \mu \mathrm{m}-1883 \mu \mathrm{m}$ (Table 2, Fig. 5.2). The papillary protrusion obtained from the difference in the height of studied papilla and interpapillary epithelium equals $706.7 \mu \mathrm{m}$ (Tables 2 and 4, Fig. 8A). The columnarlike shape of CTC was characterized by similar diameters of this structure in its basal, medial and dorsal parts

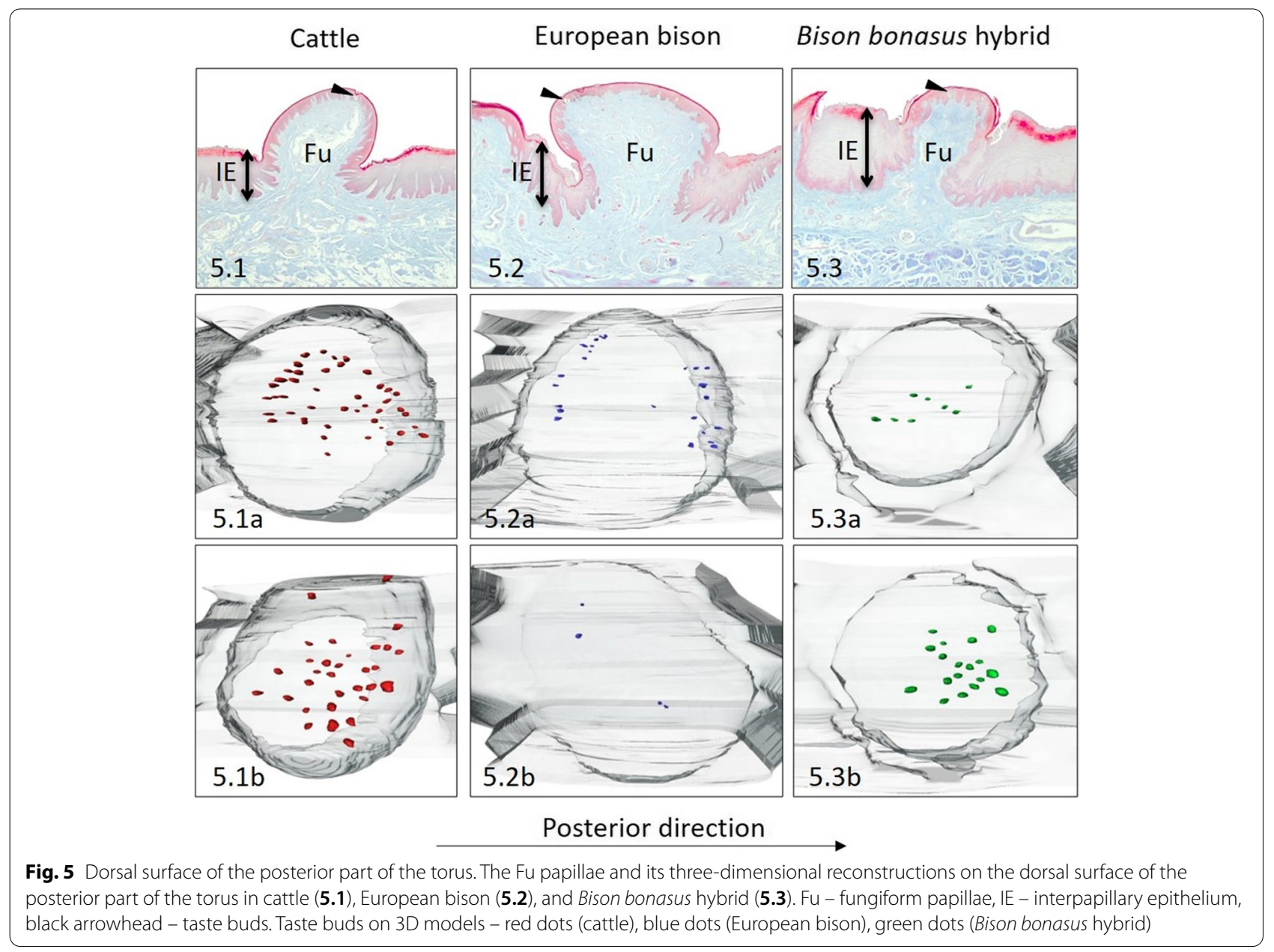


(Table 3, Figs. 5.2, 7B and 8B). The stratified squamous epithelium was $129.5 \mu \mathrm{m}$ in height, while the keratinized layer with the value of $19.2 \mu \mathrm{m}$ represented $14.8 \%$ of its thickness (Table 4, Fig. 8C). In European bison in average 14 taste buds were spread unevenly on the anterior, posterior, and lateral parts of the Fu papillae, creating small clusters (Table 1, Fig. 5.2a, 5.2b). The density of taste buds was four taste buds $/ \mathrm{mm}^{2}$, while its mean diameter reached up to $42.9 \mu \mathrm{m}$ (Tables 1 and 5).

The number and density of rounded and convex $\mathrm{Fu}$ papillae in the Bison bonasus hybrid was 46 and 2.7 papillae $/ \mathrm{cm}^{2}$, respectively (Table 1, Fig. 5.3). The diameter of Fu papillae amounted to $895 \mu \mathrm{m}$ (Table 2). The height of studied papillae reached $1221.5 \mu \mathrm{m}$, while the height of interpapillary stratified epithelium was $944.4 \mu \mathrm{m}$, so the papillary protrusion equals $277.1 \mu \mathrm{m}$ (Tables 2 and 4 , Fig. 8A). In turn, CTC had a balloon-like shape concerning its diameters in basal, medial and dorsal part (Table 3, Figs. 5.3, 7A and $8 \mathrm{~B}$ ). Furthermore, $\mathrm{Fu}$ papillae were covered with stratified squamous epithelium $113.3 \mu \mathrm{m}$ high, in which the keratinized layer represented $14.8 \%$ of his thickness (Table 4, Fig. 8C). Around 13 taste buds formed vertical and circular clusters on the dorsal surface of Fu papillae in the Bison bonasus hybrid (Table 1, Fig. 5.3a, 5.3b). The estimated density of these taste buds was 11 taste buds $/ \mathrm{mm}^{2}$, whereas its diameter was $36.5 \mu \mathrm{m}$ (Tables 1 and 5).

\section{Lateral surfaces of the torus}

The $45 \mathrm{Fu}$ papillae with a density of 0.9 papilla $/ \mathrm{cm}^{2}$ were regularly distributed on the lateral surfaces of cattle torus (Table 1). The diameter of round Fu papillae with a convex and smooth surface reached $1071.7 \mu \mathrm{m}$ (Table 2, Fig. 6.1). The differences in the height of the papillae and interpapillary stratified epithelium indicated the papillary protrusion to a height of $108.7 \mu \mathrm{m}$ (Tables 2, 4, Fig. 8A). The 3D model of CTC revealed cone-like shape in studied papillae Fu papillae (Table 3,

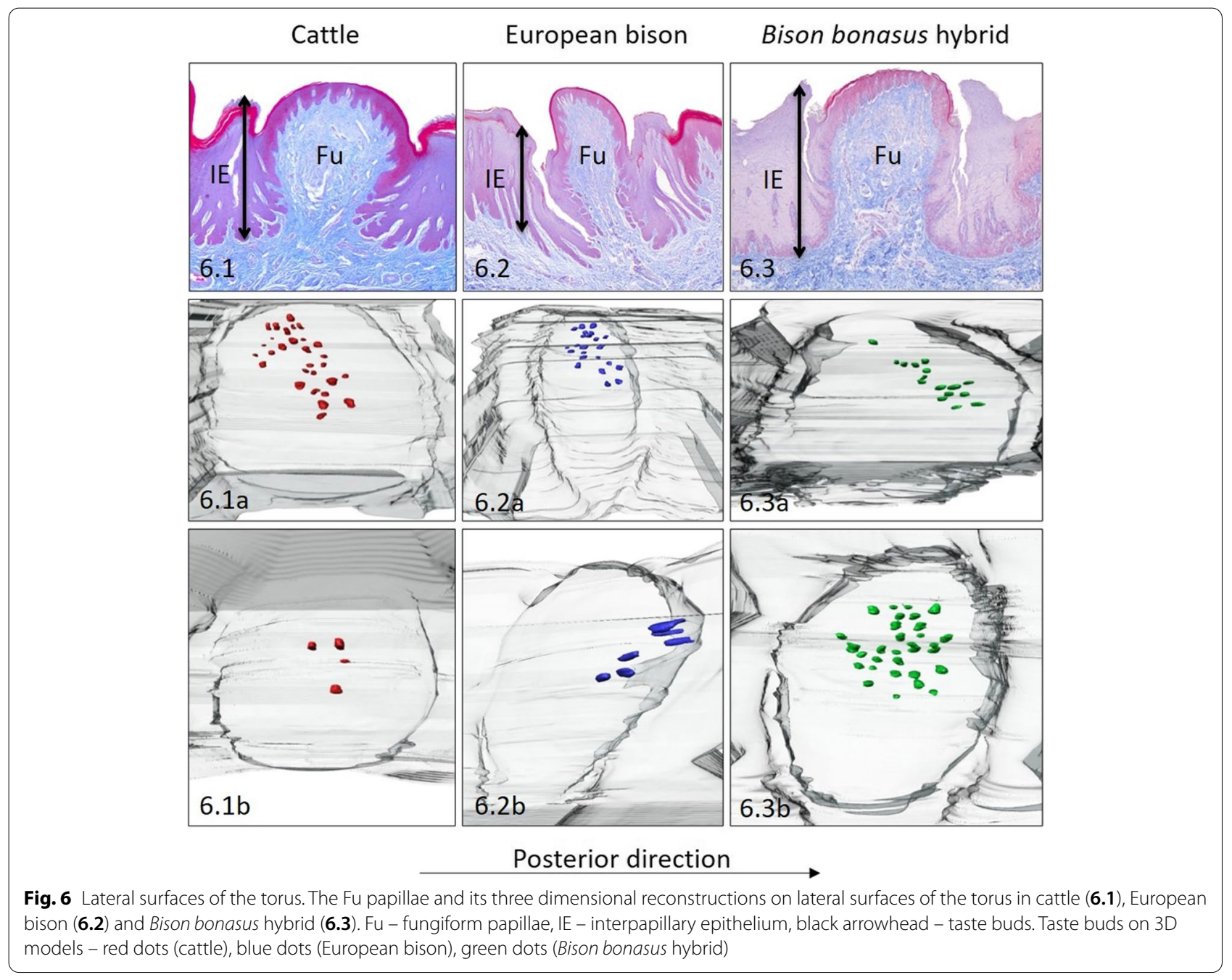



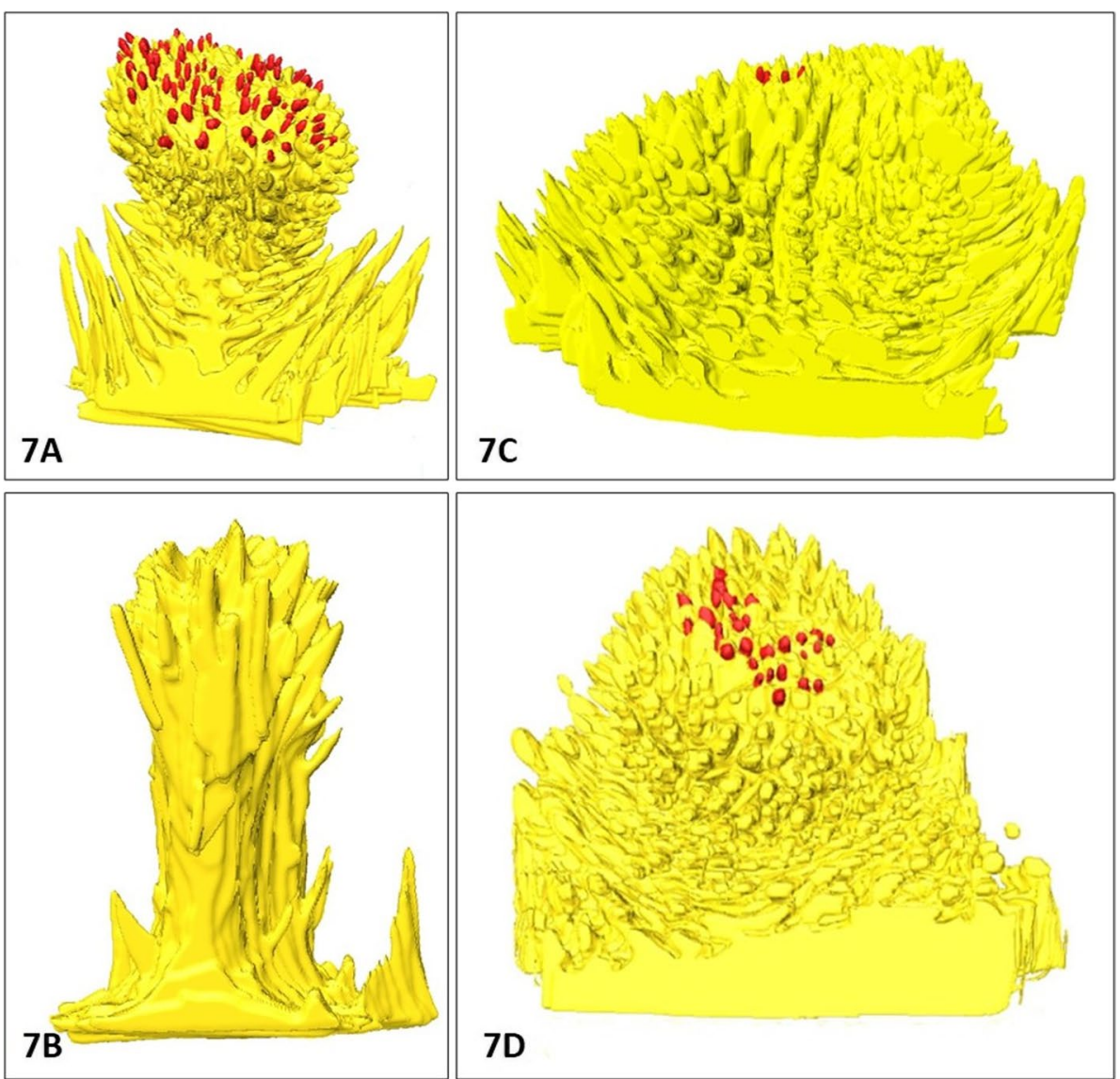

Fig. 7 The types of connective tissue cores (CTC) of Fu papillae in cattle, European bison, and Bison bonasus hybrid. 7A - balloon-like CTC on the ventral surface of the apex in cattle, 7B - columnar-like CTC on the dorsal surface of the apex in Bison bonasus hybrid, 7C - cone-like CTC on the dorsal surface of the torus in cattle, 7D - cone-like CTC on lateral surfaces of the torus in cattle. Red dots - taste buds

Figs. 6.1, 7D and 8B). The thickness of stratified squamous epithelium on Fu papillae amounted to $147.1 \mu \mathrm{m}$, whereas the thickness of his keratinized layer was expressed by $21.4 \%$ of his thickness, what represents the highest value for cattle (Table 4, Fig. 8C). In cattle, 17 taste buds were arranged centrally and on the left side of the dorsal surface of Fu papillae (Table 1, Fig. 6.1a, 6.1b). The density of taste buds in Fu papillae reached 16 taste buds $/ \mathrm{mm}^{2}$ in average (Table 1). Furthermore, the mean diameter of taste buds amounted to $44.8 \mu \mathrm{m}$ (Table 5).
In European bison number of Fu papillae on the left and right surface of torus was 46 , while the density reached 1.1 papilla $/ \mathrm{cm}^{2}$ (Table 1 ). The dorsal part of the elliptical in outline Fu papillae was convex and smooth, while their diameter equalled $655.6 \mu \mathrm{m}$ (Table 2, Fig. 6.2). The average heights of $\mathrm{Fu}$ papillae and interpapillary stratified epithelium were $1589 \mu \mathrm{m}$, and $1147.8 \mu \mathrm{m}$, respectively (Tables 2 and 4). Thus, the protrusion of Fu papillae over the epithelium was $441.2 \mu \mathrm{m}$ (Fig. 8A). The columnar-like shape of CTC was observed (Table 3, Figs. 6.2, $7 \mathrm{~B}$ and $8 \mathrm{~B})$. The epithelium covering Fu papillae was

\footnotetext{
(See figure on next page.)

Fig. 8 Graphical results of calculated data obtained during conducted studies in cattle, European bison, and Bison bonasus hybrid. A the height of Fu papillae and interpapillary epithelium (IE) with the papillary protrusion (brighter colors) above the interpapillary epithelium (darker colors), B the diameter of connective tissue cores (CTCS) on its dorsal (the darkest colors), medial (the brightest colors), and basal (intermediate colors) part in Fu papillae, $\mathbf{C}$ the height of stratified squamous epithelium and its keratinized layer (brighter colors) on the apical surface of Fu papillae. Apex D dorsal surface of the apex, Apex $V$ - ventral surface of the apex, Body $D$ - dorsal surface of the lingual body, Torus $D$ - dorsal surface of medial part of torus, Torus $P$ - dorsal surface of posterior part of torus, Torus $L$ - lateral surfaces of torus
} 

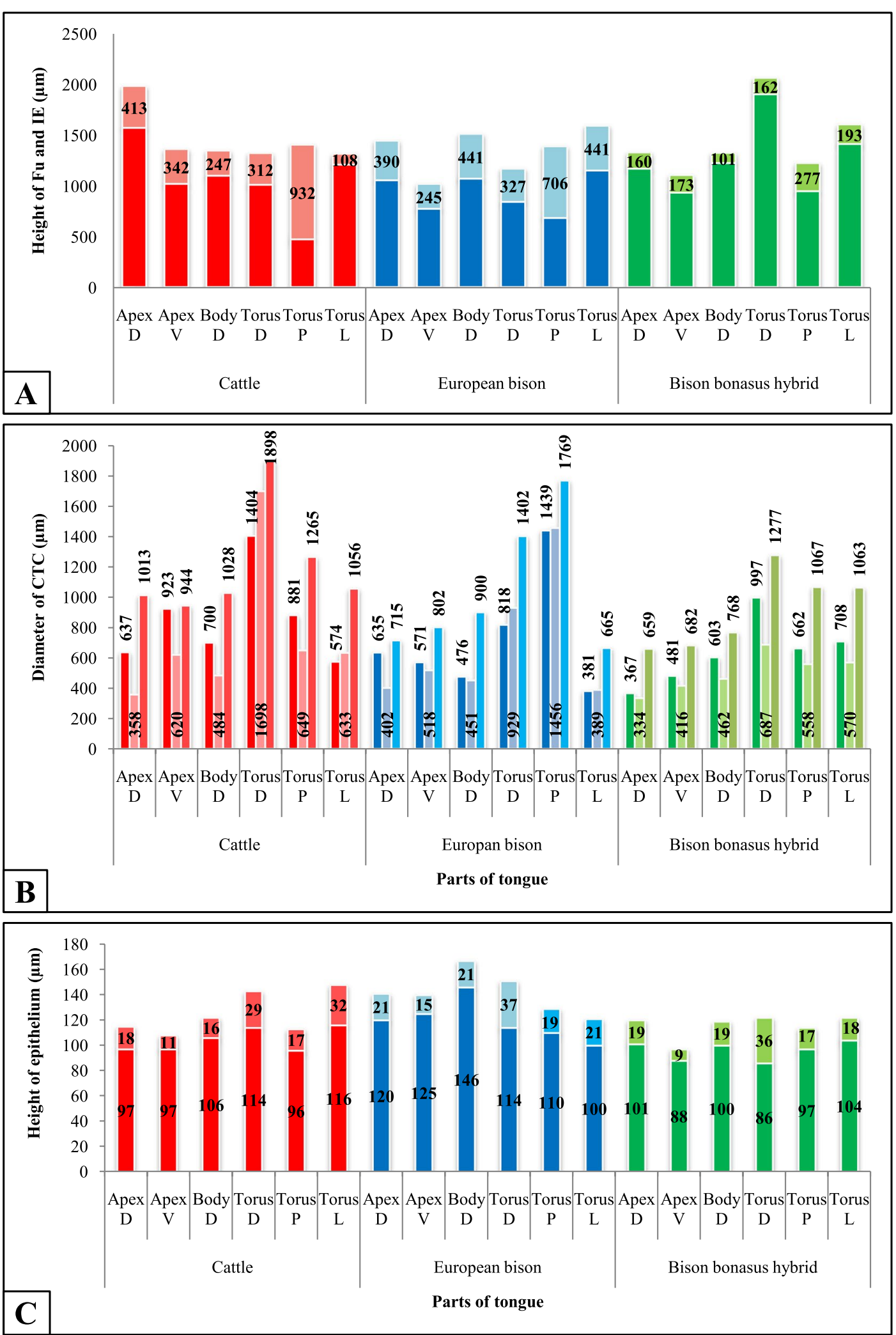

Fig. 8 (See legend on previous page.) 
$1020.9 \mu \mathrm{m}$ in high, of which $17 \%$ represented keratinized layer (Table 4, Fig. 8C). On two 3D reconstructions of Fu papillae in European bison clusters of 14 in average taste buds were observed on the left side and posterior part of surface of Fu papilla (Table 1, Fig. 6.2a, 6.2b). The density of these taste buds is 18 taste buds $/ \mathrm{mm}^{2}$ (Table 1 ). Additionally, measured diameter of taste buds ranged between $23.8 \mu \mathrm{m}-56.1 \mu \mathrm{m}$ (Table 5).

The total number of $\mathrm{Fu}$ papillae in Bison bonasus hybrid was 38 , while the density reached 1.06 papilla $/ \mathrm{cm}^{2}$ (Table 1). Round or elliptical in outline $\mathrm{Fu}$ papillae with flat and smooth dorsal surface were $964 \mu \mathrm{m}$ in diameter and $1601.9 \mu \mathrm{m}$ in height (Table 2, Fig. 6.3). The height of the interpapillary epithelium was $1408.9 \mu \mathrm{m}$, so the papillary protrusion was $193 \mu \mathrm{m}$ (Table 4, Fig. 8A). The wider dorsal diameter of Fu papilla CTC determined the balloon-like shape of this structure (Table 3, Figs. 6.3, $7 \mathrm{~A}$ and $8 \mathrm{~B})$. Fu papillae were covered by stratified squamous epithelium $121.2 \mu \mathrm{m}$ in high, of which the $14.6 \%$ represented his keratinized layer (Table 4, Fig. 8C). In the Bison bonasus hybrid, taste buds were arranged posteriorly or centrally, close to the left area of the dorsal surface of Fu papillae (Fig. 6.3a, 6.3b). The 23 taste buds were observed in average, while its density reached 19 taste buds $/ \mathrm{mm}^{2}$ (Table 1). Moreover, the mean diameter of those taste buds was $36.9 \mu \mathrm{m}$ (Table 5).

\section{Discussion}

The present microstructural study of the $\mathrm{Fu}$ papillae and its taste buds in cattle, European bison, and Bison bonasus hybrid deepens the data about the diversity of gustatory papillae revealed during earlier morphological analyses about tongues in mentioned species [27]. Based on previous data of $\mathrm{Fu}$ papillae on tongues between parental species and hybrid, the amount and density of $\mathrm{Fu}$ papillae were estimated. In cattle and the European bison the total number of the papillae over the tongue was comparable, whereas the amount Fu papillae in the Bison bonasus hybrid was ca 3.4 times higher than its parental species. So far, the amount of Fu papillae among mammals was estimated in some species of insectivores, rodents, carnivores, ruminants, and humans. The number of Fu papillae was 10-12 in the common shrew, 150 300 in mice, 114 - 221 in rat, 500 in opossum, 240 - 260 in cat, 250 in the dog, 424 - 442 in sheep, 200-250 in bovine, and around 200 in human [13, 43-47].

The obtained data showed that in parental species, 51 to $59 \%$ of the $\mathrm{Fu}$ papillae were situated on the anterior part of the tongue, i.e., apex and body, while in the Bison bonasus hybrid, this value goes up to $85 \%$. Additionally, the number of $\mathrm{Fu}$ papillae vary between the dorsal and ventral surface of the lingual apex. In parental species, the amount of $\mathrm{Fu}$ papillae on the ventral surface of the tongue is higher concerning the dorsal surface. However, the number of $\mathrm{Fu}$ papillae in the Bison bonasus hybrid on the dorsal and ventral surface of the lingual apex was almost equal and was on average 86 and $82 \%$ higher than in parental species, i.e., cattle, and European bison, respectively. Moreover, the estimated density of Fu papillae on the ventral surface of the apex in Bison bonasus hybrid reached up to 50 times more concerning other studied parts of the tongue of cattle and European bison. On the other hand, the uneven distribution of $\mathrm{Fu}$ papillae on the lingual apex was earlier observed in other studied ruminants i.e., alpaca, goat, Iraqi goat, fallow deer, and Egyptian buffalo [20, 23, 33, 48, 49].

According to behavioral studies, the relation of the mechanism of feeding and content of consumed food in ruminants, it can be assumed that the ventral surface of the apex with an accumulation of $\mathrm{Fu}$ papillae in studied ruminants is the particular contacting area of food preselection before taking a bite $[23,50]$. The second relevant part of the tongue in ruminants is the lingual torus due to the mastication of food. During cyclic side-by-side jaw movements, fine particles regurgitated from rumen are again ground by the teeth and rubbed between the surface of the tongue and the palate. During this displacement of food over the torus surface, the sensory system of $\mathrm{Fu}$ papillae is activated. For the first time, our analyses characterized $\mathrm{Fu}$ papillae on the dorsal and lateral surfaces of the torus of the tongue with particular emphasis on the posterior dorsal part of the torus. We revealed that the number and density of papillae increase from the medial to the posterior area on the dorsal surface of the torus in cattle and Bison bonasus hybrid by approximately 50-67\%. In contrast, in European bison, these values were almost constant.

Interesting results observed in parental species were that the number and density of Fu papillae on lateral surfaces of the torus of the tongue excessed values noted on the posterior part of the torus. Thus, statements about the posterolateral surfaces of the lingual torus identify them as important food tasting areas during long chewing cycles, because of $\mathrm{Fu}$ papillae and numerous Vp papillae. It gives essential advice for further studies in ruminants to take samples not only from the medial dorsal surface of the torus, which is often considered as representative area, but also from posterior and lateral surfaces of the torus.

The Fu papillae observed on 3D models in cattle, European bison, and Bison bonasus hybrid were predominantly round in outline with a convex or flattened dorsal surface. In mammalian species such as yak, cattle, cattle-yak, Iraqi goat, Iranian buffalo, hippopotamus, koala, arctic fox, Japanese badgers, and wild boar, the Fu papillae were described as mushroom- or dome-shaped 
$[3,8,9,17,18,21,25,31,33]$. The diameters of Fu papillae in studied ruminants vary over the tongue. However, the diameters of $\mathrm{Fu}$ papillae in the anterior part of the tongue were lower than on torus, from $18 \%$ in cattle, $23 \%$ in European bison to even 32\% in Bison bonasus hybrid.

Comparing the height of $\mathrm{Fu}$ papillae in cattle, European bison, and their hybrid, we stated that only in cattle, the $\mathrm{Fu}$ papillae in the anterior part of the tongue was about $16 \%$ higher than on the torus. In contrast, in European bison and hybrid, the height of $\mathrm{Fu}$ papillae on the torus was higher by 5 and 23\%, respectively. The estimating protrusion of the dorsal part of $\mathrm{Fu}$ papillae over the interpapillary stratified epithelium may be a good index explaining the rate of exposure of the dorsal surface of $\mathrm{Fu}$ papillae, containing taste buds, to taste stimuli due to food selection and/or control of swallowed food. In the studied species, the average protrusion of papillae was $392 \mu \mathrm{m}$ in cattle, $425 \mu \mathrm{m}$ in European bison, and only $177 \mu \mathrm{m}$ in European bison hybrid. On the anterior dorsal part of the tongue were note lower values of papillary protrusion compared to torus by approximately $46 \%$ in cattle, $20 \%$ in European bison, and $41 \%$ in Bison bonasus hybrid. In parental species, the papillary protrusion declined between the dorsal and ventral surface of the apex by $17 \%$ in cattle and $37 \%$ in European bison. In contrast, in the Bison bonasus hybrid, this protrusion increase by ca. $8 \%$ than the dorsal surface.

The correlated observations of 3D models parallel with serial 2D histoslides gave an occasion to the comparative description of two elements of Fu papillae, i.e., superficial epithelium, which contains taste buds and connective tissue cores (CTC).

The keratinized stratified squamous epithelium protects $\mathrm{Fu}$ papillae in ruminants against mechanical damage during chewing and rumination of food. According to our analyses, the average height of stratified squamous epithelium on $\mathrm{Fu}$ papillae was the highest in European bison, which may relate to the access to structurally diverse food available in a wild environment, changing with seasons. It is opposite to livestock, which feeds on structurally similar forage. The highest papillary epithelium coverFu papillae on the medial part of the torus in European bison and its hybrid, and the lowest values were noted on the ventral surface of the apex. The average thickness of a keratinized layer of epithelium on Fu papillae in the studied species is $21 \mu \mathrm{m}$, which is ca. $16 \%$ of the total height of the epithelium. In contrast, on the ventral surface of the tongue, these values decrease to $9-14 \mu \mathrm{m}$ and $9.5-10.5 \%$ what is important in exposes taste pores on the $\mathrm{Fu}$ papillae surface during the food selection.

The connective tissue core (CTC) of Fu papillae are the internal skeleton for capillary networks and nerve bundles, strongly attached with mucosal epithelium. So far, the shapes of CTCs as collagenous skeleton were studied in scanning electron microscopy after $\mathrm{NaOH}$ maceration of epithelia and free cells of connective tissues in rabbit, koala, hippopotamus, goat, cattle, Reeves' muntjac deer, Japanese badgers, pig, or primates $[3,4,7$, $9,25,28,51]$. These results revealed various shapes of CTCs, named flower-like, balloon-like, cauliflower-like, pine-cone-like, or columnar-like [3, 4, 7, 9, 25, 28, 51, 52].

Correlative morphometric analysis and 3D modeling of $\mathrm{Fu}$ papillae allowed to distinguished rounded in outline Fu papillae with three types of CTCs. The balloon-shaped CTCs were characterized by wide base narrowing in the medial part and often expanding near or over the surface of the interpapillary epithelium. Columnar-like type of CTC have quite similar dimensions on its dorsal and medial part, but some wider on the basal part, whereas in cone-like CTC, the width becomes smaller from base to the top of papillae. There were all three CTC types in European bison, whereas in cattle, only balloon-like and cone-like CTCs. The columnar and balloon-like CTCs were typical for Bison bonasus hybrid.

Analyzing the spatial distribution of $\mathrm{Fu}$ papillae and their CTC we revealed that on both surfaces of the lingual apex in each examined ruminant are balloon-like or columnar-like CTCs. On the torus of the tongue in cattle and European bison, there were often the cone-like CTCs, which correspond with smaller protrusion of $\mathrm{Fu}$ papillae over the mucosa surface. However, in European bison hybrid on all surfaces of lingual torus were only balloon-like types of CTCs. On the surface of CTC models in all studied species, separate elongated connective tissue processes, get deep into the thick interpapillary epithelium. Such superficial microstructures in shape/ form of vertical plices, folds, and striations providing the well attachment of the epithelia were studied previously in scanning electron microscopy [3, 4, 7, 9, 25, 28, 51]. According to Yoshimura et al. (2009) there was a primary core with numerous secondary cores in CTC of Fu papillae. Moreover, around the CTCs of Fu papillae, many separate papillary cores of the interpapillary epithelium were observed [25]. The observations of 3D CTCs models in studied ruminants showed on the surface of primary cores of a balloon- and cone-like CTC numerous short secondary cores, whereas these connective tissue structures in columnar-like CTC are rare and slender. In addition, the separate elongated intrapapillary cores were observed in the basal part of the balloon- and columnarlike type of CTCs.

During the microstructural studies of $\mathrm{Fu}$ papillae in mammalian species, in determining the number and distribution of taste buds in these papillae, three methods so far were used. The analyses of taste buds were primarily 
based on 2D observations of the cross-sections of $\mathrm{Fu}$ papillae or counting of taste pores visible on scanning electron microscopic electronograms. Such studies were conducted in Egyptian fruit bats, wild boar, pig, hippopotamus, goat, yak, wolf, and Japanese badgers [9, 15, 18, $25,31,34,49]$. The third method was indirect because of the $\mathrm{NaOH}$ macerated CTC of Fu papillae. The depressions on the dorsal surface of CTC were considered as places for taste buds [3, 7].

In current studies, we applied for the first time the three-dimensional analysis of taste buds allowed on a spatial description of distribution and counting of taste buds as a more efficient method used to describe the taste buds system in Fu papillae. Observations of serial histoslides resulted in determining the diameter of taste buds, ranging from $33 \mu \mathrm{m}$ to $48 \mu \mathrm{m}$, which may specify the size of taste buds for ruminants independent of the thickness of the stratified squamous epithelium. Studies on $3 \mathrm{D}$ models of $\mathrm{Fu}$ papillae with marked taste buds revealed that among three examined ruminants number of taste buds differs from 1 up to 64 . On the dorsal surface of the apex in the Bison bonasus hybrid, were found no taste buds in $\mathrm{Fu}$ papillae.

Previously, the number of taste buds counted from histoslides in mammalian species was often described as "numerous, several or few" taste buds [4, 9, 18, 21, 33, 41]. Estimating the number of Fu papillae and taste buds per single papilla on 3D models enabled us to calculate an approximate number of taste buds on the whole tongue. The number of taste buds was the highest in cattle, and in Bison bonasus hybrid and equals 6659 and 6620, respectively, while in European bison was estimated ca. $60 \%$ fewer taste buds, i.e., 2608. Previous publication about the number of taste buds in bovine was estimated from 1580 to 1838 taste buds in Fu papillae, which seems underestimated compared to our results [43]. In other mammalian species, like Akkaraman sheep, described 1165-1243 taste buds, while in puppy 1444 taste buds in Fu papillae were observed $[46,53]$.

According to data about the predominance of Fu papillae on the ventral surface to dorsal surface on the lingual apex we established in all examined ruminants, the number of taste buds on the ventral apex ranged from 900 to 4000 and was $60-95 \%$ higher as on the dorsal surface of the apex. Furthermore, that the calculated number of taste buds in the anterior part of the tongue in cattle, European bison, and their hybrid concerning taste buds on all torus surfaces was higher by 60,46 , and $67 \%$, respectively. A characteristic feature observed in $\mathrm{Fu}$ papillae on the anterior dorsal part of the Bison bonasus hybrid tongue was a significant decrease in the number of taste buds of 1-3 in a single papilla. The calculation showed that in cattle and European bison, as parental species, were around $94 \%$, and almost $82 \%$ more taste buds in a single papilla than in their hybrid.

The well-developed system of taste buds noticed in the anterior part of parental species tongues, i.e., apex and body, support data about the high number and density of Fu papillae, especially on the ventral surface of the lingual apex. It also confirms that the anterior part of the tongue is an important functional area in the initial analysis or preselection of food during food intake. On the other hand, a small number of taste buds per single papilla in the anterior dorsal surface of the examined hybrid tongue seems to be inconsistent with these assumptions. However, a large number of $\mathrm{Fu}$ papillae on the dorsal surface of the apex and lingual body in the Bison bonasus hybrid compensate a phenomenon of a reduced number of taste buds and in final calculations showed that the number of places of taste perception in the hybrid may be comparable to its parental species, and precisely to cattle. On torus, the total number of taste buds was grown from the medial to the posterior part about 3-5 times depending on species and reached 280-1110. Moreover, in European bison and European bison hybrid, the data showed 41 and $30 \%$ higher number of taste buds on lateral surfaces than the posterior dorsal part of the torus. In mentioned species, the total number of taste buds on the whole dorsal surface of the torus is smaller than on lateral surfaces.

Functionally, the lingual torus is associated with the process of mastication of food, which was confirmed in our analysis by the smallest total number of taste buds in Fu papillae in the medial part of the torus in all studied ruminants. In some earlier studies, giant $\mathrm{Fu}$ papillae in the posterolateral surface of the torus were observed $[25,54-57]$. Our results showed that the diameter of $\mathrm{Fu}$ papillae on lateral surfaces of the torus was similar or lower than on the other parts of the torus. Still, the total number of taste buds in this area was visibly higher, indicating the importance of lateral surfaces of the torus in taste perception. These observations defined the torus as a part of the tongue significant in both mechanical and sensory functions. Anyway, the perception of the taste of studied ruminants will be a matter for further studies on the number and types of receptors cells of taste buds.

The analysis of 3D models of Fu papillae allowed us to observe for the first time the exact distribution of taste buds on the dorsal surface of Fu papillae. The obtained results are exclusive because we defined the arrangement of taste buds as dispersed manner, but often as diagonal and vertical stripes or clusters in various shapes. In cattle, numerous taste buds were evenly dispersed or formed clusters of taste buds in the middle part of papillae, whereas in European bison, the strips were in the middle part or on borders of Fu papillae. The sparse taste buds in European bison hybrid were positioned most often 
centrally. If we compare the distribution of taste buds in many parts of the tongue, one observation seems to be exceptional. The taste buds in Fu papillae on the lingual body and on lateral surfaces of lingual torus formed strips mostly arranged perpendicularly to the direction of passage of food along with the tongue. Such tendency of grouping taste buds may allow frontal contact during transportation of food and enhance the taste perception of masticated plant food on the lingual body or during passage grinding food particles in an area between teeth and torus.

The obtained comparative data revealed some speciesspecific features in the Bison bonasus hybrid, which is rare in the case of interspecies ruminant achieved in 1970 in Poland and still occurred in farms. The Bison bonasus hybrid called żubroń was crossbred as a farm ruminant due to the desire to establish a new breed of beef cattle adapted to free breeding [58]. Considering data obtained in the Bison bonasus hybrid, quite surprising was ca. 3.5 times larger total amount of Fu papillae than in parental species, and the fact that on each part of the Bison bonasus hybrid tongue, the number and density of $\mathrm{Fu}$ papillae per $1 \mathrm{~cm}^{2}$ exceeded values observed in cattle and European bison. However, the protrusion of Fu papillae on each part of tongue was ca. $50 \%$ lower papillae then in its parental species. The observations of 3D models of $\mathrm{Fu}$ papillae also indicated a small amount or a lack of taste buds in Fu papillae on the lingual apex or the presence of only balloon-like CTCs in Fu papillae on the lingual torus. Our research has shown an interesting similarity of many traits of Fu papillae between the Bison bonasus hybrid and the maternal species i.e., domesticated cattle. These common features are almost equal number of taste buds in cattle and the hybrid as number and density of $\mathrm{Fu}$ papillae on the particular parts of torus as well the thickness of the stratified squamous epithelium on Fu papillae. These listed features in Bison bonasus hybrid and earlier described anatomical data might be considered as species-specific, which could be functional implications and/ or are consequences arising after hybridization.

\section{Conclusions}

Quantitative and qualitative data from microscopic observation and computer-aided analysis of 3D models of $\mathrm{Fu}$ papillae in three species of ruminants provided new data about the variety of the distribution and microscopic features of Fu papillae over the surface of the tongues. In this respect, two regions of the tongue, i.e., the ventral surface of the lingual apex and posterolateral surfaces of the lingual torus, were designated. The regional differences obtained an evaluation of amount, the density of $\mathrm{Fu}$ papillae, and taste buds stay with feeding habits and kind of forage typical for domesticated farm species like cattle and wild living European bison. The characteristic of taste buds system in terms as a number, as well its different arrangement indicated an efficient system of receptions of taste in cattle and less developed complex system in European bison hybrid, which may correlate with evolutionary changes in frame of domestication. The 3D models of Fu papillae in all studied species of ruminants allowed to describe firstly three types of CTC of Fu papillae,

As an innovative method, the three-dimensional analysis proved to be a comprehensive tool for evaluating detailed structures of $\mathrm{Fu}$ papillae, i.e., the papillae outline, the shape of CTC, and distribution and number of taste buds. Based on numerous results obtained from 3D models of Fu papillae, we state that the application of this modern visualization technique is the most suitable tool to describe gustatory papillae with taste buds system in mammals and could be helpful in normal, pathological, and clinical assessments.

\section{Materials and methods}

The observations and 3D models of Fu papillae were conducted on one tongue of Bison bonasus hybrid and its parental species: cattle and European bison. The cattle tongue was obtained in a cattle slaughterhouse near Poznań, the European bison was from Poznań zoological garden, while the hybrid was from the farm in Karolew, near Poznań in Poland. Each tongue was fixed in 10\% neutral formaldehyde. A total of $41 \mathrm{Fu}$ papillae were dissected from the dorsal and ventral surface of the apex, body of the tongue, and for first time from three areas i.e., dorsal, posterior, and lateral surfaces of torus of tongue for three-dimensional analysis.

Tissues dissected for histology and 3D reconstructions proceeded into paraplast. Embedded tissues were serially cut on a microtome (Leica RM 2055) into $8 \mu \mathrm{m}$ slices. All slides were dye using Masson-Goldner method and closed using synthetic resin DePex. Each slide was observed and documented using a light microscope Axioskop 2 plus (Zeiss) with digital camera Gryphax. For each section, magnification $\times 1.25$ was used. A record of lost or unsuitable slices within serial slides was conducted. Depend on the size of $\mathrm{Fu}$ papilla 100-300 slices per papilla were used for reconstruction. In order to create 3D reconstructions of $\mathrm{Fu}$ papillae, their CTCs, and taste buds, a conversion to a single channel (green channel), an alignment, a recalculation into uniform coordinates, a segmentation, a resampling in $\mathrm{X}, \mathrm{Y}$, and $\mathrm{Z}$ direction, a surface generation and adjustments steps in professional computer software, called Amira were conducted (Thermo Fisher Scientific, ver.2020). Moreover, to better visualization 
of 3D models, one animation of the Fu papilla from the ventral surface of the apex in cattle also in Amira were prepared (Additional file 1).

Morphometric analysis conducted on $2-3 \mathrm{Fu}$ papillae dissected from particular parts of examined ruminants tongues. Depended on its size, 8-10 cross-sections from the medial part of the papilla were selected. Furthermore, on each perpendicular cross-section, 3-5 measurements of the height of Fu papillae and its stratified squamous epithelium, the diameter of $\mathrm{Fu}$ papillae, the height of interpapillary epithelium, and the diameter of taste buds were taken. These data were obtained using MultiScan computer system v.18.03 (CSS, Warsaw, Poland). Average values of obtained data with its graphical analysis were estimated in Microsoft Excel (2010). The number and density of Fu papillae were established from macroscopic pictures of particular parts of examined tongues, whereas the number and density of taste buds were obtained from 3D models of Fu papillae.

Anatomical nomenclature of the structures of the tongue was taken from Nomina Anatomica Veterinaria (2017) [59].

\section{Abbreviations}

CTC: Connective tissue core; Fu papillae: Fungiform papillae; Fo papillae: Foliate papillae; LM: Light microscopy; SEM: Scanning electron microscopy; Vp papillae: Vallate papillae.

\section{Supplementary Information}

The online version contains supplementary material available at https://doi. org/10.1186/s12917-021-03111-5.

\section{Additional file 1.}

\section{Acknowledgments}

The authors greatly appreciate Mr. Henryk Ordanik, Bison bonasus hybrid breeder, for the opportunity to get the tongues of examined hybrid used in these studies.

\begin{abstract}
Authors' contributions
The design and concept of the study were conceptualized by authors (BP, $\mathrm{HJ})$. The collecting materials, preparation of histological slides, photographic documentation of fungiform papillae, preparation of 3D reconstructions, morphometric analysis (BP, KSS). Preparation of manuscript and corrections were provided by authors (BP, $\mathrm{HJ})$. The authors read and approved the final manuscript.
\end{abstract}

\section{Funding}

Research conducted by the statutory funding No. 506.539.04.00 of the Faculty of Veterinary Medicine and Animal Science Poznan University of Life Sciences, Poland.

\section{Availability of data and materials}

All data analyzed during this study are included in this published article. Any additional data are available upon request to the corresponding author.

\section{Declarations}

Ethics approval and consent to participate

According to Polish law and the EU directive (no. 2010/63/EU) the experiments conducted within the study do not require approval of the Local Ethical
Committee for Experiments on Animal in Poznan. We declare that methods were performed in accordance with the relevant guidelines and regulations of Faculty of Veterinary Medicine and Animal Sciences at the Poznan University of Life Sciences. Due to dissected ruminants tongue used during the studies, we obtained written informed consent to use the organs in our study from all owners of the animals.

All methods were carried out in accordance with relevant guidelines and regulations. The study was carried out in compliance with the ARRIVE guidelines.

\section{Consent for publication}

Not applicable.

\section{Competing interests}

The authors declare that they have no competing interests.

Received: 16 June 2021 Accepted: 13 December 2021

Published online: 07 January 2022

\section{References}

1. Kardong KV. Vertebrates. Comparative anatomy, function, evolution. 6th ed. China: Mc Graw Hill; 2011.

2. Yoshimura K, Kobayashi K. A comparative morphological study on the tongue and the lingual papillae of some marine mammals - particularly of four species of odontoceti and zalophus. Shigaku=Odontology. 1997;85:385-407.

3. Kobayashi K, Kumakura M, Yoshimura K, Nonaka K, Murayama T, Henneberg M. Comparative morphological study of the lingual papillae and their connective tissue cores of the koala. Anat Embryol. 2003;206:24754. https://doi.org/10.1007/s00429-002-0296-z.

4. Kobayashi K, Kumakura M, Yoshimura K, Tkahashi M, Zeng JH, Kageyama I, et al. Comparative morphological studies on the stereo structure of the lingual papillae of selected primates using scanning electron microscopy. Ann Anat. 2004;186:525-30. https://doi.org/10.1016/s0940-9602(04)80101-8.

5. Kumar S, Bate LA. Scanning electron microscopy study of the tongue papillae in the pig (Sus scrofa). Microsc Res Techniq. 2004;63:253-8. https://doi.org/10.1002/jemt.20036.

6. Jackowiak H, Godynicki S. The distribution and structure of the lingual papillae on the tongue of the bank vole Clethrionomys glareolus. Folia Morphol (Warsz). 2005;64:326-33.

7. Nonaka K, Zheng JH, Kobayashi K. Comparative morphological study on the lingual papillae and their connective tissue cores in rabbits. Okijamas Folia Anat Jpn. 2008:85:57-66.

8. Jackowiak H, Godynicki S, Skieresz-Szewczyk K, Trzcielińska-Lorych J. Scanning electron microscopic study of the lingual papillae in the Arctic fox (Alopex lagopus L., 1758). Anat Histol Embryol. 2009a;38:377-81. https://doi.org/10.1111/j.1439-0264.2009.00957.x.

9. Yoshimura K, Shindo J, Kageyama I. Light and scanning electron microscopic study on the tongue and lingual papillae of the Japanese badgers, Meles meles anakuma. Okijamas Folia Anat Jpn. 2009a;85:119-27.

10. Dasgupta K, Singh A, Ireland WP. Taste bud density in circumvallate and fungiform papillae of the bovine tongue. Histol Histopath. 1990;5:169-72.

11. Pastor JF, Moro JA, Verona JAG, Gato A, Represa JJ, Barbosa E. Morphological study by scanning electron microscopy of the lingual papillae in the common European bat (Pipistrellus pipistrellus). Arch Oral Biol. 1993;38:597-9.

12. Kurtul J, Atalgin SH. Scanning electron microscopic study on the structure of the lingual papillae of the Saanen goat. Small Rumin Res Elsevier. 2008;80:52-6. https://doi.org/10.1016/j.smallrumres.2008.09.003.

13. Jackowiak H, Godynicki S, Jaroszewska M, Wilczyńska B. Scanning electron microscopy of lingual papillae in the common shrew, Sorex araneus. L Anat Histol Embryol. 2004;33:290-3. https://doi.org/10.1111/j.14390264.2004.00551.x.

14. Jackowiak H. Scanning electron microscopy study of the lingual papillae in the European mole (Talpa europea, L., Talpidae). Anat Histol Embryol. 2006;35:190-5. https://doi.org/10.1111/j.1439-0264.2005.00661.x.

15. Jackowiak H, Trzcielińska-Lorych J, Godynicki S. The microstructure of lingual papillae in the Egyptian fruit bat (Rousettus aegyptiacus) as observed by light microscopy and scanning electron microscopy. Arch Histol Cytol. 2009b;72:13-21. https://doi.org/10.1679/aohc.72.13. 
16. Sari EK, Harem MK, Harem IS. Characteristics of dorsal lingual papillae of Zavot cattle. J Anim Vet Adv. 2010;9:123-30.

17. Mahabady MK, Morovvati $H$, Khazaeil K. A microscopic study of lingual papillae in Iranian Buffalo (Bubalus bubalus). Asian J Anim Vet Adv. 2010:5:154-61. https://doi.org/10.3923/ajava.2010.154.161.

18. Shao B, Long R, Ding Y, Wang J, Ding L, Wang H. Morphological adaptations of yak (Bos grunniers) tongue to the foraging environment of the Qinghai-Tibetan plateau. J Anim Sci. 2010;88:2594-603.

19. Emura S, Okumura T, Chen H. Morphology of the lingual papillae in the Egyptian rousette bat (Rousettus aegyptiacus). Okijamas Folia Anat. Jpn. 2012;89:61-6. https://doi.org/10.2535/ofaj.89.61.

20. Emura S, El-Bakary NER. Morphology of the lingual papillae of Egyptian Buffalo (Bubalus bubalis). Okajimas Folia Anat Jpn. 2014;91:13-7. https://doi.org/10.2535/ofaj.91.13.

21. Ding Y, Yu S, Shao B. Anatomical and histological characteristic of the tongue and tongue mucosa linguae in the cattle-yak (Bos taurus $\times$ Bos grunniens). Front Biol. 2016;11:141-8. https://doi.org/10.1007/s11515-016-1393-3.

22. El-Bakary NER, Abomandour MMA. Morphological studies of the tongue of the Egyptian water Buffalo (Bubalus bubalis) and their lingual papillae adaptation for its feeding habits. Anat Histol Embryo. 2017;12:34-40. https://doi.org/10.1111/ahe.12292.

23. Jackowiak H, Skubis J, Łakomy P, Nasiadka P, Godynicki S. Anatomy of the tongue and microstructure of the lingual papillae in the fallow deer Dama dama (Linnaeus, 1758). Mamm Biol. 2017:85:14-23.

24. Emura S. Morphology of the lingual papillae in the Asian golden cat. Okijamas Folia Anat Jpn. 2018;95:19-22. https://doi.org/10.2535/ofaj.95.19.

25. Yoshimura K, Hama N, Shindo J, Kobayashi K, Kageyama I. Light and scanning electron microscopic study on the tongue and lingual papillae of the common hippopotamus, Hippopotamus amphibious amphibious. Anat Rec. 2009b;292:921-34.

26. Samuelson DA. Textbook of veterinary histology. St. Louis: Saunders Elsevier; 2007.

27. Plewa B, Jackowiak H. Macro- and microscopic study on the tongue and lingual papillae of Bison bonasus hybrid as an interspecific species (Bos taurus x Bison bonasus). Microsc Res Tech. 2020;83:1241-50.

28. Zheng J, Kobayashi K. Comparative morphological study on the lingual papillae and their connective tissue cores (CTC) in reeves' muntjac deer (Muntiacus reevesi). Ann Anat. 2006;188:555-64.

29. Harem MK, Harem IS, Sari EK, Aydin MF. Light and scanning electron microscopic study of the dorsal lingual papillae of the Goitered gazelle (Gazella subgutturosa). J Anim Vet Adv. 2011;10:1906-13. https://doi. org/10.3923/javaa.2011.1906.1913.

30. Erdogan S, PerezW. Anatomical and scanning electron microscopic studies of the tongue and lingual papillae in the chital deer (Axis axis, Erxleben 1777). Acta Zool. 2014;95:484-92. https://doi.org/10.1111/azo.12044.

31. Chamorro CA, Fernandez JG, de Paz P, Pelaez B, Anel L. Scanning electron microscopy of the wild boar and pig lingual papillae. Histol Histopath. 1994;9:657-67.

32. Pfeiffer CJ, Levin M, Lopes MAF. Ultrastructure of the horse tongue: further observations on the lingual integumentary architecture. Atan Histol Embryol. 2000;29:37-43.

33. Jabbar AJ. Macroscopical and microscopical observations of the tongue in the Iraqi goat (Capra hircus). Int J Adv Res. 2014;2:642-8.

34. Haligur A, Ozkadif S, Alan A. Light and scanning electron microscopic study of lingual papillae in the wolf (Canis /upus). Microsc Res Tech. 2018;82:501-6. https://doi.org/10.1002/jemt.23193.

35. Ross MH, Romrell LJ, Kaye GI. Histology. A text and atlas. 3rd ed. Baltimore: Williams \& Wilkins; 1995.

36. Barlow LA. A taste for development. Neuron. 1999;22:209-12. https:// doi.org/10.1016/S0896-6273(00)81081-8

37. Jung H, Akita K, Kim J. Spacing patterns on tongue surface - gustatory papilla. Int J Dev Biol. 2004;48:157-61. https://doi.org/10.1387/ijdb.041824hj.

38. Rozin P. The selection of foods by rats, humans, and other animals. In: Advances in the study of behaviour, vol. 6: Elsevier; 1976. p. 21-76.

39. Forbes $J M$, Kyriazakis I. Food preferences in farm animals: why don't they always choose wisely? Proc Nutr Soc. 1995;54:429-40. https://doi. org/10.1079/PNS19950012.

40. Behrens M, Meyerhof W. Mammalian bitter taste perception. In: Korsching S, Meyerhof W, editors. Chemosensory systems in mammals, fishes, and insects. Results and problems in cell differentiation. Berlin: Springer; 2009. p. 77-96. https://doi.org/10.1007/400_2008_5.
41. Erdogan S, PerezW. Anatomical and scanning electron microscopic characteristics of the tongue in the pampas deer (Cervidae: Ozotoceros bezoarticus, Linnaeus 1758). Microsc Res Tech. 2013;76:1025-34. https:// doi.org/10.1002/jemt.22263.

42. El-Sharaby AA, El-Gendy SA, Alsafy MA, Nomir AG, Wakisaka S. Morphological variations of the vallate papillae in some mammalian species. Anat Sci Int. 2014;89:161-70. https://doi.org/10.1007/s12565-013-0215-9.

43. Davies RO, Kare MR, Cagan RH. Distribution of taste buds on fungiform and circumvallate papillae of bovine tongue. Anat Rec. 1979;195:443-6. https://doi.org/10.1002/ar.1091950304.

44. Spielman Al, Brand JG. Collection of taste tissue from mammals. In: Spielman Al, Brand JG, editors. Experimental cell biology of taste and olfaction. Current techniques and protocols. Boca Raton: CRC Press; 1995. p. 25-33. https://books.google.pl/books?id=UAoMLgi_cMgC\&printsec=frontcover $\& h l=p \mid \# v=$ onepage\&q\&f=true. Accessed 22 Feb 2021

45. Robinson PP, Winkles PA. Quantitative study of fungiform papillae and taste buds on the cat's tongue. Anat Rec. 1990;225:108-11.

46. Unsal S, Aktumsek A, Celik I, Sur E. The number and distribution of fungiform papillae and taste buds in the tongue of young and adult Akkaraman sheep. Revue Med Vet. 2003;154:709-14.

47. Cheng LHH, Robinson PP. The distribution of fungiform papillae and taste buds on the human tongue. Arch Oral Biol. 1991;36:583-9. https://doi.org/10.1016/0003-9969(91)90108-7.

48. Erdogan S, Arias SV, Perez W. Morphofunctional structure of the lingual papillae in three species of South American Camelids: Alpaca, Guanaco, and Llama. Microsc Res Tech. 2016;79:61-71. https://doi.org/10. 1002/jemt.22604.

49. Mahdy MAA, Abdalla KEH, Mohamed SA. Morphological and scanning electron microscopic studies of lingual papillae of the tongue of the goat (Capra hircus). Microsc Res Tech. 2020:1-11. https://doi.org/10. 1002/jemt.23649.

50. Bergvall UA. Food choice in fallow deer - experimental studies of electivity. Stockholm University, Sweden. 2007. Doctoral dissertation.

51. Kobayashi K, Kumakura M, Yoshimura K. Stereo structural differences of lingual papillae and their connective tissue cores in three kinds of Artiodactyla. Recent Advances in Microscopy of Cells, Tissues and Organs. 1997:357-61.

52. Kobayashi K, Jackowiak H, Frackowiak H, Yoshimura K, Kumakura M Kobayashi K. Comparative morphological study on the tongue and lingual papillae of horses (Perissodactyla) and selected ruminantia (Artiodactyla). It J Anat Embryol. 2005;2:55-63.

53. Holliday JC. Total distribution of taste buds on the tongue of the pup. Ohio J Sci. 1940;40:337-44.

54. Inatomi M, Kobayashi K. Comparative morphological studies on the tongue and lingual papillae of the Japanese black bear (Carnivora) and the mountain goat (Artiodactyla). Odontology. 1999;87:313-28.

55. Mack A, Singh A, Gilroy C, Ireland W. Porcine lingual taste buds: a quantitative study. Anat Rec. 1997;247:33-7. https://doi.org/10.1002/(SICI) 1097-0185(199701)247:1\%3C33::AID-AR5\%3E3.0.CO;2-G.

56. Yamaguchi T, Asami T, Kobayashi K. Comparative anatomical studies on the stereo structure of the lingual papillae and their connective tissue cores in the Japanese serow and Bighorn sheep. Arch Histol Jpn. 2002;44:127-41.

57. Yoshimura K, Kumakura M, Koizumi K, Abe T, Yamaguchi T, Kobayashi K. Comparative morphological study on the stereo-structure of the lingual papillae and their connective tissue cores of the pronghorn. Odontology. 2000;88:47-57.

58. Krasińska M. Hybrydy żubra i bydła domowego. Wrocław: Ossolineum; 1988.

59. Nomina Anatomica Veterinaria. 6th Ed. Submitted by the International Committee on Gross Veterinary Anatomical Nomenclature (I.C.V.G.A.N.) to the World Association of Veterinary Anatomists. Published on the website of the W.A.V.A. 2017.

\section{Publisher's Note}

Springer Nature remains neutral with regard to jurisdictional claims in published maps and institutional affiliations. 